\title{
ASSESSMENT OF NOTCHED STRUCTURAL STEEL COMPONENTS USING FAILURE ASSESSMENT DIAGRAMS AND THE THEORY OF CRITICAL DISTANCES
}

\author{
V. Madrazo, S. Cicero, T. García \\ Dpto. Ciencia e Ingeniería del Terreno y de los Materiales, Universidad de Cantabria, Av/ Los Castros \\ s/n, 39005, Santander, Cantabria, Spain, ciceros@unican.es
}

\begin{abstract}
When the structural integrity of notched components is analysed, it is generally assumed that notches behave as cracks, something which generally provides overconservative results. The proposal of this paper consists, on the one hand, in the application of the Theory of Critical Distances for the estimation of the notch fracture toughness and, therefore, for the conversion of the notched situation into an equivalent cracked situation in which the material develops a higher fracture resistance. On the other hand, once the notch fracture toughness has been defined, the assessment is performed using the Failure Assessment Diagram methodology, and assuming that the notch effect on the limit load is negligible. The methodology has been applied to $336 \mathrm{CT}$ notched fracture specimens made of two different structural steels, covering temperatures from the corresponding lower shelf up to the upper shelf, providing satisfactory results and a noticeable reduction in the overconservatism derived from the analyses in which the notch effect is not considered.
\end{abstract}

\section{INTRODUTION: NOTCH EFFECT, THE THEORY OF CRITICAL DISTANCES AND FAILURE ASSESSMENT DIAGRAMS}

There are many situations where the defects responsible for structural failure are not sharp. Actually, notched components develop a fracture resistance that is greater than that developed by cracked components (e.g., [1-7]) and this, generally, is directly related to the load-bearing capacity of the component. Hence, the development of an adequate methodology for the assessment of the notch effect would reduce the conservatism in many practical situations.

There are two main failure criteria in notch theory: the global fracture criterion and local fracture criteria $[2,3]$. The global criterion establishes that failure occurs when the notch stress intensity factor reaches a critical value, $\mathrm{K}_{\rho}{ }^{\mathrm{c}}$ :

$$
\mathrm{K}_{\rho}=\mathrm{K}_{\rho}^{\mathrm{c}}
$$

This approach is totally analogous to that used in cracks, but its application is very limited because of the lack of analytical solutions for $\mathrm{K}_{\rho}$ (as there are for $\mathrm{K}_{\mathrm{I}}$ ) or/and standardized procedures for the experimental definition of $\mathrm{K}_{\rho}^{\mathrm{c}}$.

Local criteria are based on the stress field on the notch tip. Among them, the Point Method (PM), the Line Method (LM) and the Finite Fracture Mechanics stand out [8], all of them being different versions of the Theory of Critical Distances (TCD) and, then, using a characteristic material length parameter (the critical distance, L) when performing fracture assessments [8]:

$$
L=\frac{1}{\pi}\left(\frac{K_{c}}{\sigma_{0}}\right)^{2}
$$

$\mathrm{K}_{\mathrm{c}}$ is the material fracture toughness and $\sigma_{0}$ is a characteristic material strength parameter (the inherent strength) that must be calibrated. Only in those materials with linear-elastic behaviour at both the macro and the micro scales (e.g., ceramics), does $\sigma_{0}$ coincide with the ultimate tensile strength $\left(\sigma_{\mathrm{u}}\right)[8]$.

The notch analysis following these methodologies is relatively simple. For example, the PM [9] establishes that fracture occurs when the stress reaches the inherent strength $\left(\sigma_{0}\right)$ at a distance from the defect tip equal to L/2: 


$$
\sigma\left(\frac{L}{2}\right)=\sigma_{0}
$$

For its part, the LM [10] assumes that fracture occurs when the average stress along a distance equal to $2 \mathrm{~L}$ (starting from the defect tip), reaches the inherent strength, $\sigma_{0}$ :

$$
\frac{1}{2 L} \int_{0}^{2 L} \sigma(r) d r=\sigma_{0}
$$

The basics of the FFM, a little more complex and based on the Griffith theory [11], can be found in [8, 12]

When fracture toughness is determined by using notched specimens, and the equations provided by the standards (e.g., [13]) for the definition of the material fracture toughness are applied, the corresponding measured fracture resistance may be noticeably higher than the fracture toughness (e.g., $\mathrm{K}_{\mathrm{c}}$ ) obtained in normalised cracked specimens, given that, as mentioned above, the load-bearing capacity of the notched material is higher than that developed by the same material when it is cracked. This fracture resistance developed by the material in notched conditions is generally referred to as the apparent fracture toughness or notch fracture toughness, $\mathrm{K}^{\mathrm{N}}$.

The different methodologies belonging to the TCD can be applied to the analysis of the load-bearing capacity of components containing notches. Moreover, these methodologies may generate predictions of the notch fracture toughness $\left(\mathrm{K}_{\mathrm{c}}^{\mathrm{N}}\right)$ exhibited by components containing U-shaped notches [14]. If the PM is used, it is necessary to consider the stress distribution on the notch tip provided by Creager and Paris [15], which is equal to that ahead of the crack tip but displaced a distance equal to $\rho / 2$ along the $x$-axis:

$$
\sigma(r)=\frac{K_{I}}{\sqrt{\pi}} \frac{2(r+\rho)}{(2 r+\rho)^{3 / 2}}
$$

In [7], the Creager-Paris distribution and FE results are compared, providing reasonably similar predictions of the stress field on the notch tip. Considering both the condition defining the PM (equation (3)) and the definition of the critical distance L (equation (2)), and establishing that failure takes place when $\mathrm{K}_{\mathrm{I}}$ is equal to $\mathrm{K}^{\mathrm{N}}$, equation (6) may be easily obtained [8]:

$$
K_{c}^{N}=K_{c} \frac{\left(1+\frac{\rho}{L}\right)^{3 / 2}}{\left(1+\frac{2 \rho}{L}\right)}
$$

Analogously, the application of the LM provides equation (7):

$$
K_{c}^{N}=K_{c} \sqrt{1+\frac{\rho}{4 L}}
$$

Further details on the TCD, its different proposals for notch effect analysis, and the comparison between the corresponding predictions, can be found in the literature (e.g., $[8,16])$.

Finally, Failure Assessment Diagrams (FADs) constitute one of the main engineering tools for the assessment of fracture-plastic collapse processes in cracked components (e.g., [17-21]). These diagrams present a simultaneous assessment of both fracture and plastic collapse processes by using two normalised parameters, $\mathrm{K}_{\mathrm{r}} \mathrm{y} \mathrm{L}_{\mathrm{r}}$, whose expressions are:

$$
K_{r}=\frac{K_{I}}{K_{c}}
$$




$$
L_{r}=\frac{P}{P_{L}}
$$

$P$ being the applied load, $P_{L}$ being the limit load, $K_{I}$ being the stress intensity factor, and $K_{c}$ the material fracture resistance measured by the stress intensity factor. Therefore, $\mathrm{L}_{\mathrm{r}}$ evaluates the structural component situation against plastic collapse, and $\mathrm{K}_{\mathrm{r}}$ evaluates the component against fracture. Once the component assessment point is defined through the coordinates $\left(\mathrm{K}_{\mathrm{r}}, \mathrm{L}_{\mathrm{r}}\right)$, it is necessary to define the component limiting conditions (i.e., those leading to final failure). With this purpose, the Failure Assessment Line (FAL) is defined, so that if the assessment point is located between the FAL and the coordinate axes, the component is considered to be under safe conditions, whereas if the assessment point is located above the FAL, the component is considered to be under unsafe conditions. The critical situation (failure) is that in which the assessment point lies exactly on the FAL, whose general expression is:

$$
K_{r}=f\left(L_{r}\right)
$$

Figure 1 shows an example of this kind of assessment, where the crack-like assessment of the defect leads to unsafe conditions (the assessment point is located above the FAL).

\section{COMBINING THE TCD AND FADS FOR THE STRUCTURAL INTEGRITY ASSESSMENT OF NOTCHED COMPONENTS}

The notch assessment methodology proposed here combines the TDC with the FAD methodology [7], through the introduction of a notch correction in the $\mathrm{K}_{\mathrm{r}}$ parameter. Thus, the definition of the $\mathrm{K}_{\mathrm{r}}$ parameter in notch analysis would be:

$$
K_{r}=\frac{K_{I}}{K_{c}^{N}}
$$

If the LM is applied, the corresponding equations would be:

$$
K_{r}=\frac{K_{I}}{K_{c}^{N}}=\frac{K_{I}}{K_{c} \sqrt{1+\frac{\rho}{4 L}}}
$$

Analogous expressions would be obtained when using the PM or the FFM corrections. In any case, regardless of the expression being used for $\mathrm{K}^{\mathrm{N}}$, this methodology proposes to convert a notched material with $\mathrm{K}_{\mathrm{IC}}$ as the fracture resistance into an equivalent situation with a cracked material having a higher fracture resistance, equal to $\mathrm{K}^{\mathrm{N}}{ }_{\mathrm{c}}[7]$.

In order to complete the FAD analysis it is necessary to define the $\mathrm{L}_{\mathrm{r}}$ parameter, which depends on the limit load (equation (9)). Plastic collapse occurs through the yielding of the remanent section, so that in a perfectly plastic material, it can be defined by the material yield stress and the defect dimensions, with no influence of the radius existing on the defect tip. In [22] the low influence of the notch radius on the limit load is demonstrated.

If this methodology is compared to the assessment of notches as if they were cracks (a conservative practice, as mentioned above), equation (12) would produce a reduction of the $\mathrm{K}_{\mathrm{r}}$ parameter and, then, a vertical displacement (downwards) of the assessment point, as shown in Figure 1. An analogous approach would be obtained if the notch correction were applied on the FAL expression (equation (10)), with totally equivalent results [7].

There are other proposals for the notch correction in FAD analysis. One of them is that proposed by Horn and Sherry [23, 24]. This work has demonstrated a weak dependence of the R6 Option 3 failure assessment curves on the notch radius [23]. These authors state that this independence of the Option 3 failure assessment curve from the notch root radius does not contradict experimental observations of increasing resistance to fracture with increasing notch radius, given that the benefit associated with increasing notch radius is quantified by the increase in the notch fracture toughness. 
The derivation of $\mathrm{K}_{\mathrm{r}}$ and $\mathrm{L}_{\mathrm{r}}$ following this approach may be consulted in [23], although these authors also consider that the notch effect in $\mathrm{L}_{\mathrm{r}}$ is generally very low.

Meanwhile, Pluvinage [25] proposes combining the FAD methodology with the global notch criterion. Thus, the coordinate $\mathrm{Kr}$ is defined as:

$$
K_{r}=\frac{K_{\rho}}{K_{\rho}^{c}}
$$

$\mathrm{K}_{\rho}$ is obtained by using the volumetric method [25] and $\mathrm{K}_{\rho}{ }^{\mathrm{c}}$ is the fracture toughness measured from notched specimens with the same radius as the defect being analysed [25] (the notch fracture toughness). This methodology does not consider any notch effect in $L_{r}$ parameter.

Finally, Matvienko [26] develops specific FADs for notches, based on the cohesive zone model, local fracture criterion and the notch tip stress distribution proposed by Creager and Paris [15].

\section{EXPERIMENTAL PROGRAMME AND RESULTS}

\subsection{Specimen description}

The methodology proposed here for the assessment of notches through Failure Assessment Diagrams has been applied to two ferritic-pearlitic steels: S275JR and S355J2. In order to analyse the notch effect along the different zones of the material fracture behaviour (lower shelf, ductile-to-brittle transition zone and upper shelf), an experimental program composed of 336 CT specimens has been performed. 180 of the specimens correspond to steel S275JR, and 156 correspond to steel S355J2. This difference is justified by the fact that in the latest case it was only possible to perform tests at just one temperature $\left(-196^{\circ} \mathrm{C}\right)$ within the material lower shelf, as shown below. The CT specimens used here guarantee high constraint conditions due to the defect depth and the type of loading (e.g., [6,21]), so the loss of constraint analysed here is basically restricted to that caused by the notch effect. In any case, both possible sources of loss of constraint are independent, and different (analogous) expressions may be found in [6,24] for their simultaneous analysis.

For each combination of material and test temperature, specimens containing six different types of notch radii were tested: $0 \mathrm{~mm}$ (crack-like defects), $0.15 \mathrm{~mm}, 0.25 \mathrm{~mm}, 0.50 \mathrm{~mm}, 1.0 \mathrm{~mm}$ and $2.0 \mathrm{~mm}$, as shown in Figure 2.

The reference temperature, $\mathrm{T}_{0}$, which is the one corresponding to a median fracture toughness $\mathrm{K}_{\mathrm{Jc}}$ of 100 $\mathrm{MPam}^{1 / 2}$ obtained in $25 \mathrm{~mm}$ thick cracked specimens, was obtained applying ASTM 1921-10 [27] and following the multi-temperature option. The corresponding reference temperatures were $-26^{\circ} \mathrm{C}$ for steel S275JR and $-133^{\circ} \mathrm{C}$ for steel S355J2.

Once the reference temperatures were known, the testing temperatures at the lower shelf, the DBTZ and the upper shelf were defined, as shown in Table 1.

Tables 2 and 3 gather the complete experimental program, with the material, the geometry, the testing temperature and the load-bearing capacity (LBC) results of every single tested CT specimen

\subsection{Mechanical characterization}

In order to obtain the tensile properties of the two materials at the different temperatures, which are necessary to perform the FAD analysis, the two materials were tested at those temperatures shown in Table 1 and also at room temperature $\left(+20^{\circ} \mathrm{C}\right)$, following ASTM E8/E8M-11 [28]. Tables 4 and 5 gather the results. It can be observed how, in the two steels being analysed, the lower the temperature, the higher the yield stress, the ultimate tensile strength and the Young's modulus (this effect is also accompanied by a reduction in ductility parameters). Also, both steels satisfy their specifications at room temperature. 
Concerning the fracture toughness of the two materials at the different temperatures being analysed, this was obtained from the cracked specimens included in the experimental programme.

The values of $\mathrm{K}_{\mathrm{c}}$ were obtained following ASTM 1820 [13] and, therefore, using the following equations:

$$
K_{c}=\sqrt{J_{c} \frac{E}{1-v^{2}}}
$$

where $\mathrm{J}_{\mathrm{c}}$ is the J-integral at onset of cleavage fracture, E is the Young's modulus and $v$ is the Poisson's ratio [13]:

$$
J_{c}=J_{e}+J_{p}=\frac{\left(1-v^{2}\right)\left(K_{e}\right)^{2}}{E}+\frac{\eta A_{p}}{B b_{0}}
$$

where $\mathrm{J}_{\mathrm{e}}$ and $\mathrm{J}_{\mathrm{p}}$ are, respectively, the elastic and plastic components of $\mathrm{J}_{\mathrm{c}}, \eta$ is a dimensionless constant, $A_{p}$ is the plastic area under the load-displacement curve, $b_{0}$ is the initial remaining ligament and $K_{e}$ is the elastic stress intensity factor at instability [13]:

$$
K_{e}=\left(\frac{P}{B \cdot W^{0.5}}\right) \frac{2+\frac{a}{W}}{\left(1-\frac{a}{W}\right)^{3 / 2}} \cdot\left(0.886+4.64\left(\frac{a}{W}\right)-13.32\left(\frac{a}{W}\right)^{2}+14.72\left(\frac{a}{W}\right)^{3}-5.60\left(\frac{a}{W}\right)^{4}\right)
$$

The $\mathrm{K}_{\mathrm{c}}$ values for each material and temperature are gathered in Table 6 for steel S275JR, and Table 7 for steel S355J2. The results are provided for 50\% and $95 \%$ confidence levels.

Considering the results obtained in the experimental program, $\mathrm{K}_{\mathrm{c}}$ may represent the following parameters:

- $\quad \mathrm{K}_{\mathrm{Jc}}$, which is the fracture toughness at fracture instability prior to the onset of significant stable tearing defect extension [13]. This measure is independent of in-plane dimensions but may depend on thickness.

- $\quad \mathrm{K}_{\mathrm{JQ}}$, which is the fracture toughness at fracture instability after the onset of significant stable tearing defect extension. This is the case occurring when a relatively high temperature (upper shelf) allows the defect to develop important amounts of tearing before final fracture.

Although $\mathrm{K}_{\mathrm{Jc}}$ and $\mathrm{K}_{\mathrm{JQ}}$ depend (to a different extent) on the geometry of the specimens, this geometry is kept constant here, so for the purpose of the FAD analysis this question is not an issue.

Analogously, equations (14) to (16) were applied to the experimental results obtained in notched specimens, providing the corresponding values of $K^{\mathrm{N}}$, which are graphically shown in figures 3 and 4 .

\subsection{Calibration of $\mathrm{L}$}

In order to apply equation (12), it is necessary to determine the value of $\mathrm{L}$ for each combination of material and temperature. This can be done by a combination of limited experimental results and finite elements modelling or by fitting $\mathrm{K}^{\mathrm{N}}{ }_{\mathrm{c}}$ experimental results through equations (6) and (7). Here, the latest option through equation (7) has been chosen, given the high number of experimental results. The fitting process has been performed by using the Line Method, but similar results would be obtained in case of using the Point Method (e.g., [8]). Moreover, the small differences that may appear when applying the Line Method or the Point Method have even minor influence in the final FAD analysis, given that the critical distance $(\mathrm{L})$ is squared in the notch corrections applied to estimate the notch fracture toughness.

Figures 3 and 4 show the notch fracture toughness results of the 336 tests (as mentioned above, obtained through the application of equations (14) to (16) [13]), and the corresponding best fitting that provides the value of the critical distance, $\mathrm{L}$. Table 8 summarises the results. 
It can be observed how the obtained values of $\mathrm{L}$ at different temperatures are not constant for a given material, although they all have the same order of magnitude at low temperatures. Also, for the two materials, the value of $L$ at the corresponding maximum testing temperature presents a much higher value than those obtained at lower temperatures.

\section{FAD ANALYSIS FOR NOTCHED SPECIMENS}

This section shows the FAD analysis of the 336 CT specimens included in the experimental program, before and after the notch correction proposed in this paper. The notch correction has been applied using the value of the fracture toughness associated to a 95\% confidence level, according to good engineering practice. Expressions of FAD were taken from FITNET FFS Procedure [17] (Option 1), whereas $\mathrm{K}_{\mathrm{I}}$ and $\mathrm{P}_{\mathrm{L}}$ solutions were taken from [21].

Here it should be noted that when the notch radius increases, the specimen conditions vary from plain strain conditions in cracked conditions up to plain stress conditions for these specimens with higher radii.

When the notch fracture toughness associated to a particular material, notch radius and temperature is lower than the value provided by equation (17), then it is assumed that plain strains conditions are dominant, and the corresponding $\mathrm{P}_{\mathrm{L}}$ solution is given by equation (18) [8]:

So, when $\mathrm{K}^{\mathrm{N}}$ values are lower than the limit established by

$$
\begin{aligned}
& K_{c}^{N}[\text { plane - strain limit }]=\sigma_{y}(B / 2.5)^{0.5} \\
& P_{L}=1.455 \eta B b \sigma_{y}
\end{aligned}
$$

where $\mathrm{B}$ is the thickness of the specimen, $\mathrm{b}$ is the remaining ligament, and $\eta$ follows equation (19):

$$
\eta=\sqrt{\left(\frac{2 a}{b}\right)^{2}+\frac{4 a}{b}+2}-\left(\frac{2 a}{b}+1\right)
$$

where $\mathrm{a}$ is the defect size.

On the other hand, when $\mathrm{K}^{\mathrm{N}}$, values are higher than the limit established by equation (20) [8], it is considered that plane stress conditions are dominant, the $\mathrm{P}_{\mathrm{L}}$ solution being that provided by equation (21)

$$
\begin{aligned}
& K_{c}^{N}[\text { plane }- \text { stress onset }]=\sigma_{y}(\pi B)^{0.5} \\
& P_{L}=1.072 \eta B b \sigma_{y}
\end{aligned}
$$

For those situations located between the limits established by equations (17) and (20), the $\mathrm{P}_{\mathrm{L}}$ solution has been obtained by interpolation of equations (18) and (21).

\subsection{Lower shelf}

Figures 5 and 6 show the results obtained at temperatures corresponding to the lower shelf of the two materials being analysed. It can be observed how the assessment points at failure are generally located far from the FAL, providing overconservative results. Also, once the notch correction is applied, the assessment points approach to the FAL and, therefore, the results are much more close to the real physics. It is interesting to observe how the assessment points after the notch correction follow the shape of the FAL.

Finally, in the three analysed situations, the majority of the results remain conservative (safe), although with a significant reduction in the conservatism. There are just three specimens, one per combination of 
material and temperature, providing unsafe results (corresponding with assessment points at failure within the theoretical safe area).

\subsection{Ductile-to-brittle transition zone results}

Figure 7 presents the results for steel S275JR. It can be observed how the assessment points (at failure) of the specimens when there are no notch corrections are located, in many cases, far from the critical condition defined by the FAL. This, again, means that the failure load predictions derived from the FAD analysis would have been much lower than the actual ones (showing the conservatism of this type of analysis). However, once the notch corrections have been applied, the corresponding assessment points are located much closer to the FAL, providing better predictions to the failure loads

On this occasion, all the results remain safe (conservative) after the notch correction. Finally, it can be observed that the higher the temperature, the lower the notch effect of the notch correction in terms of the proximity of the corrected assessment point to the FAL.

Figure 8 shows the results for steel S355J2. The benefits of the notch correction are clear again, with noticeable reductions in conservatism. In this case, one of the results is unsafe. Finally, as observed in steel S275JR, the higher the temperature, the lower the effect of the notch correction.

\subsection{Upper shelf results}

Figures 9 and 10 show the results obtained in the upper shelf. The conservatism of the results when there is no notch correction is generally much lower than that observed at lower temperatures, something that agrees with the smaller notch effect at high plastic conditions.

The notch corrections are also less significant, but still provide better approaches to the FAL. The most significant corrections have been obtained in steel $\mathrm{S} 355 \mathrm{~J} 2$ at $-50^{\circ} \mathrm{C}$. In all cases the results are safe.

\section{CONCLUSIONS}

This paper presents a methodology for the assessment of structural components containing notch-type defects. The notch effect generates an increase in the load-bearing capacity which, if not considered (assessment of notches as crack-like defects), may lead to overconservative results.

The methodology combines the use of Failure Assessment Diagrams (FADs) with the Theory of Critical Distances (TCD). The notch fracture toughness provided by the TCD is obtained and subsequently introduced in the $\mathrm{K}_{\mathrm{r}}$ parameter of the FAD assessment, which, after this correction, continues as in crack assessments (the notch effect in the limit load is assumed to be negligible).

The methodology has been applied to $336 \mathrm{CT}$ specimens of two structural steels, covering temperatures from the lower shelf up to the upper shelf, and including the ductile-to-brittle transition zone. It has been observed how the application of the proposed methodology provides much better, and generally safer, results than those obtained when the notch nature is not considered. Also, it has been demonstrated that, for each material, the lower the temperature, the more significant the notch correction.

\section{ACKNOWLEDGMENTS}

The authors of this work would like to express their gratitude to the Spanish Ministry of Science and Innovation for the financial support of the project MAT2010-15721: "Análisis de integridad estructural en defectos tipo entalla" (Structural integrity assessments of notch-type defects), on the results of which this paper is based.

\section{REFERENCES}

[1] L.S. Niu, C. Chehimi, G. Pluvinage, Stress field near a large blunted V notch and application of the concept of notch stress intensity factor to the fracture of very brittle materials, Engineering Fracture Mechanics, 49 (1994), 325-335. 
[2] G. Pluvinage, Fatigue and fracture emanating from notch; the use of the notch stress intensity factor, Nuclear Engineering and Desing, 185 (1998), 173-184.

[3] Y. Bao, Z. Jin, Size effects and a mean-strength criterion for ceramics, Fatigue \& Fracture of Engineering Materials \& Structures, 16, 8 (1993), 829-835.

[4] W. Fenghui, Prediction of intrinsic fracture toughness for brittle materials from the apparent toughness of notched-crack specimen, Journal of Materials Science, 35, 10 (2000), 2543-2546.

[5] A. Seweryn, A. Łukaszewicz, Verification of brittle fracture criteria for elements with V-shaped notches, Engineering Fracture Mechanics, 69, 13 (2002), 1487-1510.

[6] S. Cicero, F. Gutiérrez-Solana, J.A. Álvarez, Structural integrity assessment of components subjected to low constraint conditions, Engineering Fracture Mechanics, 75, 10 (2008), 3038-3059.

[7] S. Cicero, V. Madrazo, I.A. Carrascal, R. Cicero, Assessment of notched structural components using Failure Assessment Diagrams and the Theory of Critical Distances, Engineering Fracture Mechanics, 78, 16 (2011), 2809-2825.

[8] D. Taylor, The theory of critical distances: a new perspective in fracture mechanics, Elsevier, London, 2007.

[9] R.E. Peterson, Methods of correlating data from fatigue test of stress concentration specimens, in: Stephen Timoshenko Sixtieth Anniversary, Macmillan, New York, 1938, 179-186.

[10] H. Neuber, Kerbspannungslehre: Grundlagen für genaue Festigkeitsberechnung mit Berücksichtigung von Konstruktionsform und Werkstoff, Springer-Verlag, Berlin, 1958.

[11] A.A. Griffith, The Phenomena of Rupture and Flow in Solids, Philosophical Transactions of the Royal Society of London. Series A, Containing Papers of a Mathematical or Physical Character, 221 (1921), 163-198.

[12] D. Taylor, P. Cornetti, N. Pugno, The fracture mechanics of finite crack extension, Engineering Fracture Mechanics, 72,7 (2005), 1021-1038.

[13] ASTM E1820-11e11, Standard Test Method for Measurement of Fracture Toughness, American Society of Testing and Materials, Philadelphia, 2011.

[14] C. Chen, H. Pan, Collection of papers on fracture of metals, Metallurgy Industry Press, (1978), 197219.

[15] M. Creager, P.C. Paris, Elastic field equations for blunt cracks with reference to stress corrosion cracking, International Journal of Fracture Mechanics, 3, 4 (1967), 247-252.

[16] L. Susmel, D. Taylor, The Theory of Critical Distances as an alternative experimental strategy for the determination of KIc and $\Delta$ Kth, Engineering Fracture Mechanics, 77, 9 (2010), 1492-1501.

[17] M. Kocak, S. Webster, J. Janosch, R. Ainsworth, R. Koers, FITNET Fitness-for-service (FFS), Procedure vol. 1, GKSS, Hamburgo, 2008.

[18] BS 7910:2005, Guide to methods for assessing the acceptability of flaws in metallic structures, British Standard Institution, Londres, 2005.

[19] R6, Assessment of the integrity of structures containing defects, British Energy Generation Limited, Rev. 4, 2007. 
[20] API 579-1/ASME FFS-1, Fitness-for Service, American Society of Mechanical Engineers, 2007.

[21] T.L. Anderson, Fracture mechanics: Fundamentals and applications, CRC Press, Florida, 2005.

[22] A.G. Miller, Review of limit loads of structures containing defects, International Journal of Pressure Vessels and Piping, 32 (1988), 197-327.

[23] A.J. Horn, A.H. Sherry, An engineering assessment methodology for non-sharp defects in steel structures - Part I: Procedure development, International Journal of Pressure Vessels and Piping, 89 (2012), 137-150.

[24] A.J. Horn, A.H. Sherry, An engineering assessment methodology for non-sharp defects in steel structures - Part II: Procedure validation and constraint analysis, International Journal of Pressure Vessels and Piping, 89 (2012), 151-161.

[25] G. Pluvinage, Pipe-defect assessment based on the limit analysis, failure-assessment diagram, and subcritical crack growth, Materials Science, 42, 1 (2006), 127-139.

[26] Y.G. Matvienko, Local fracture criterion to describe failure assessment diagrams for a body with a crack/notch, International Journal of Fracture, 124, 3-4 (2003), 107-112.

[27] ASTM E1921-13, Standard Test Method for Determination of Reference Temperature, To, for Ferritic Steels in the Transition Range, American Society of Testing and Materials, Philadelphia, 2013.

[28] ASTM E8/E8M-11, Standard Test Methods for Tension Testing of Metallic Materials, American Society of Testing and Materials, Philadelphia, 2011. 


\section{Figures}

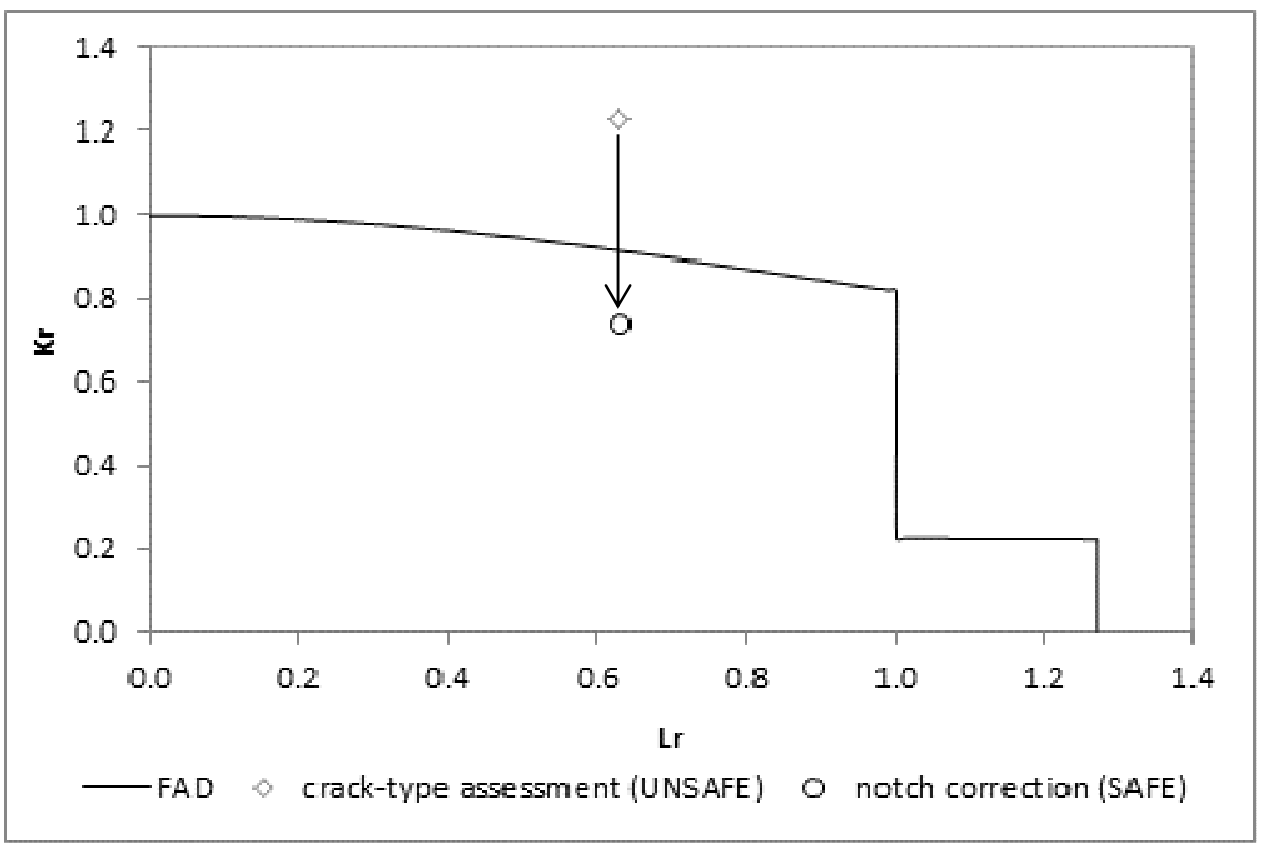

Figure 1. FAD analysis (initiation). The crack-type FAD assessment leads to an unsafe situation; after the application of the notch correction the situation is safe. 


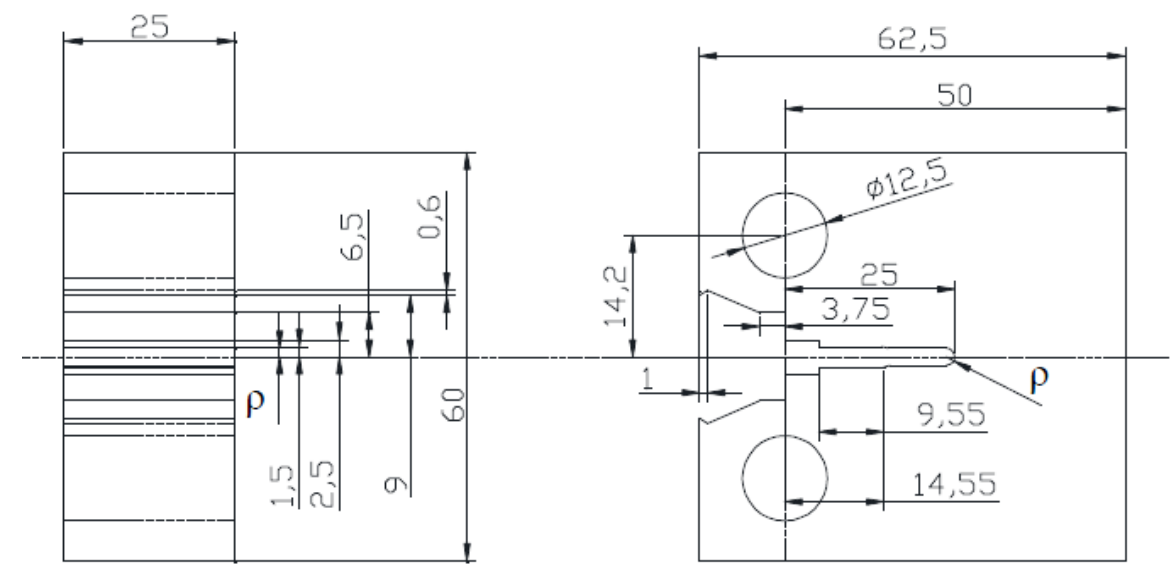

Figure 2. Schematic showing the geometry of the specimens (dimensions in $\mathrm{mm}$ ). $\rho$ varying from $0 \mathrm{~mm}$ up to $2.0 \mathrm{~mm}$ 

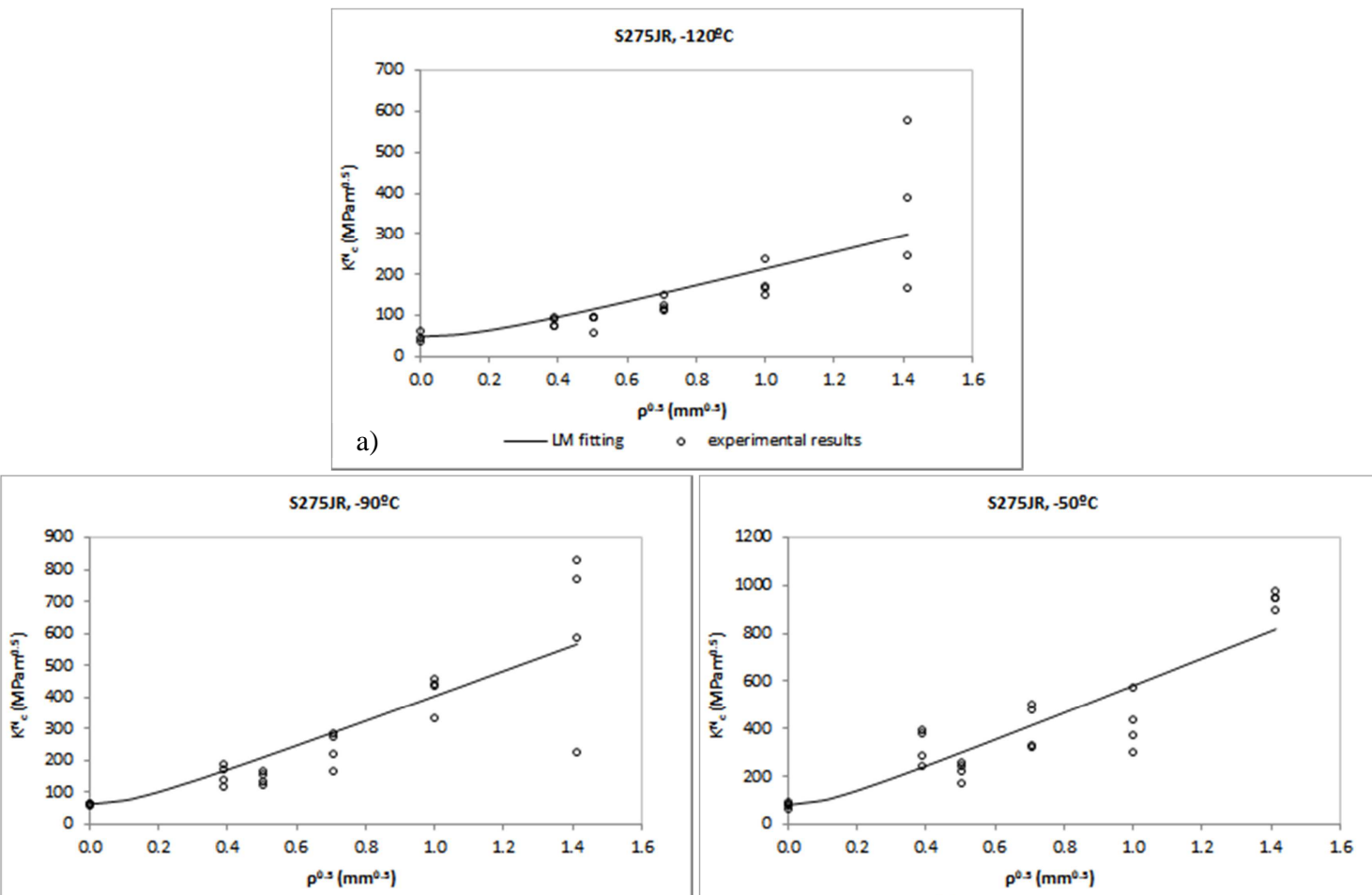

b)

_L IM fitting $\quad$ experimental results

c) —uM fitting $\quad \circ$ experimental results

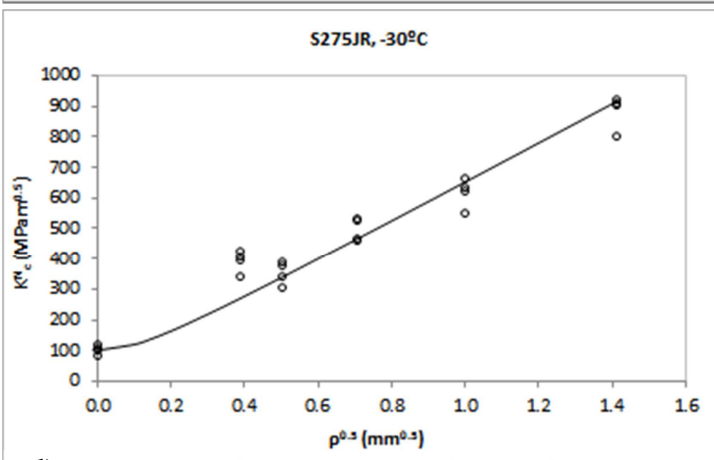

d)

- UM fitting $\circ$ experimental results

S275JR, $40^{\circ} \mathrm{C}$
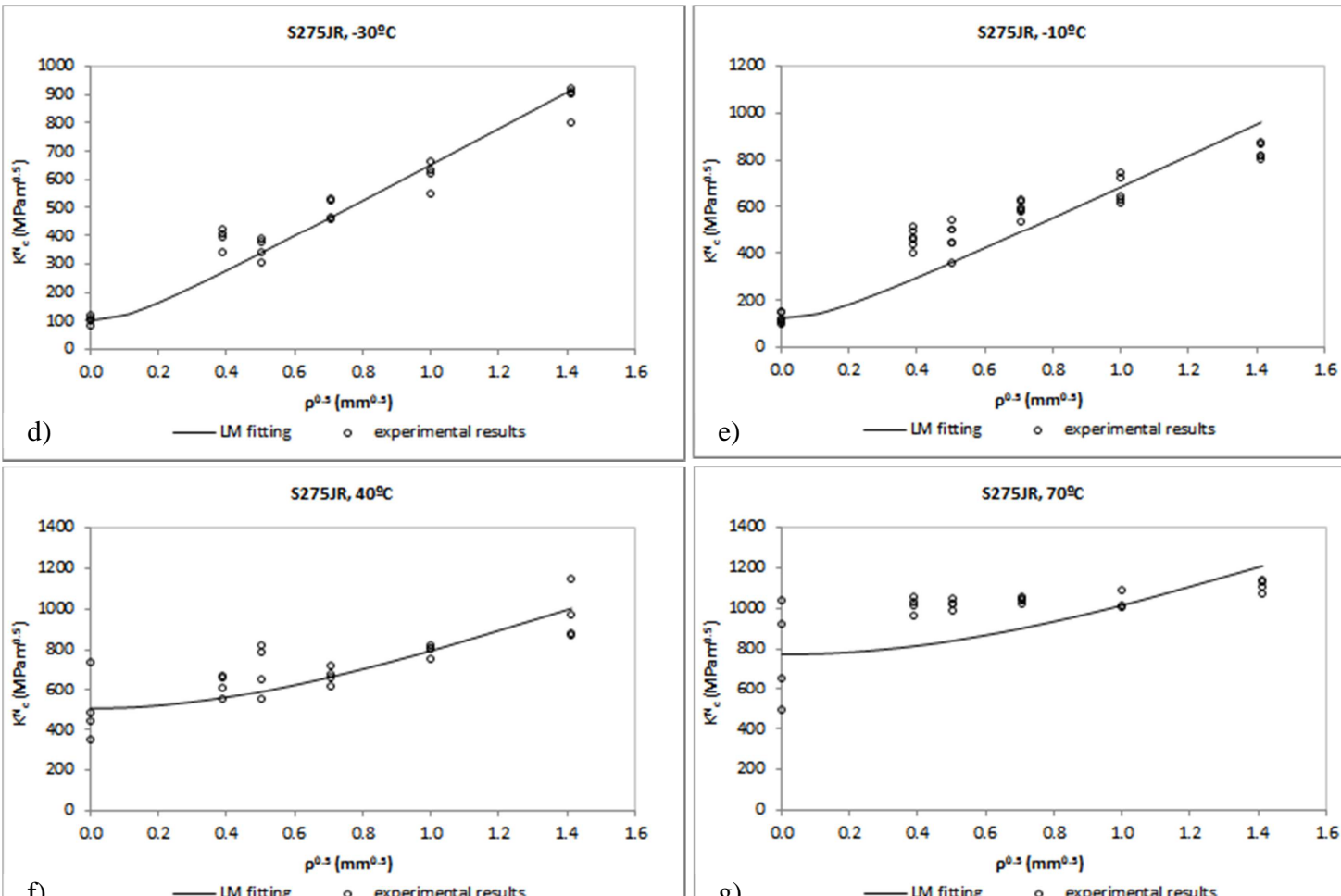

e)

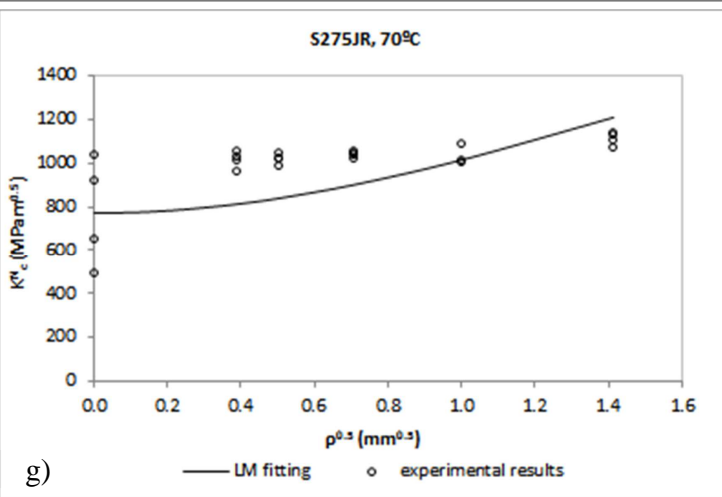

Figure 3. Experimental notch fracture toughness results, Line Method (LM) fitting and derivation of the corresponding critical distance. Steel S275JR. a) $-120^{\circ} \mathrm{C}$; b) $-90^{\circ} \mathrm{C}$; c) $-50^{\circ} \mathrm{C}$; d) $-30^{\circ} \mathrm{C}$; e) $-10^{\circ} \mathrm{C}$; f) $40^{\circ} \mathrm{C}$; g) $70^{\circ} \mathrm{C}$. 

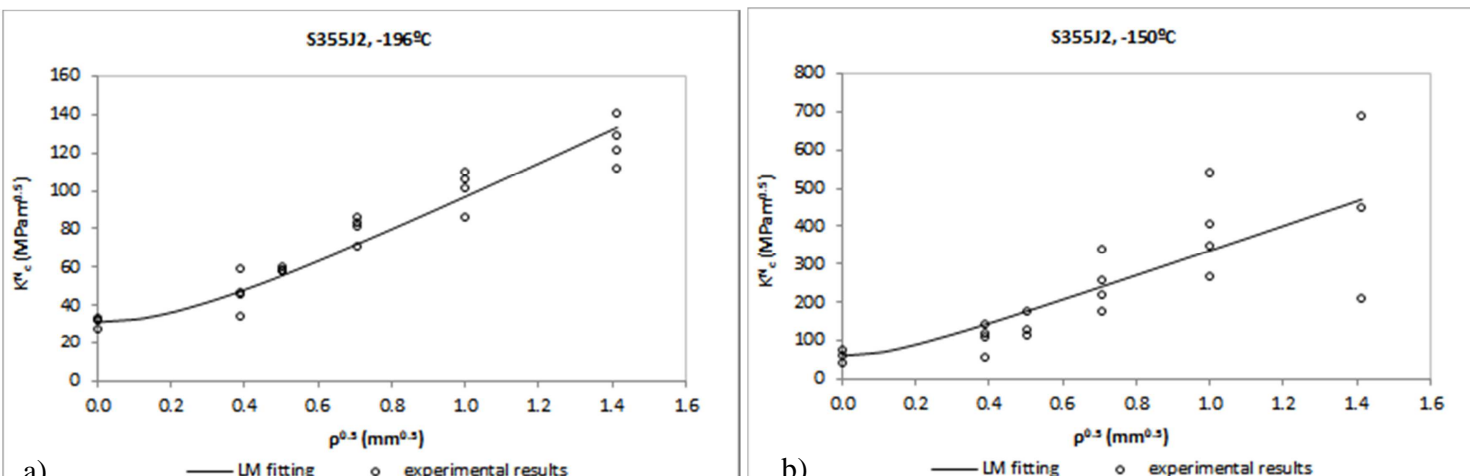

a)

— UM fitting $\quad \circ$ experimental results

b)
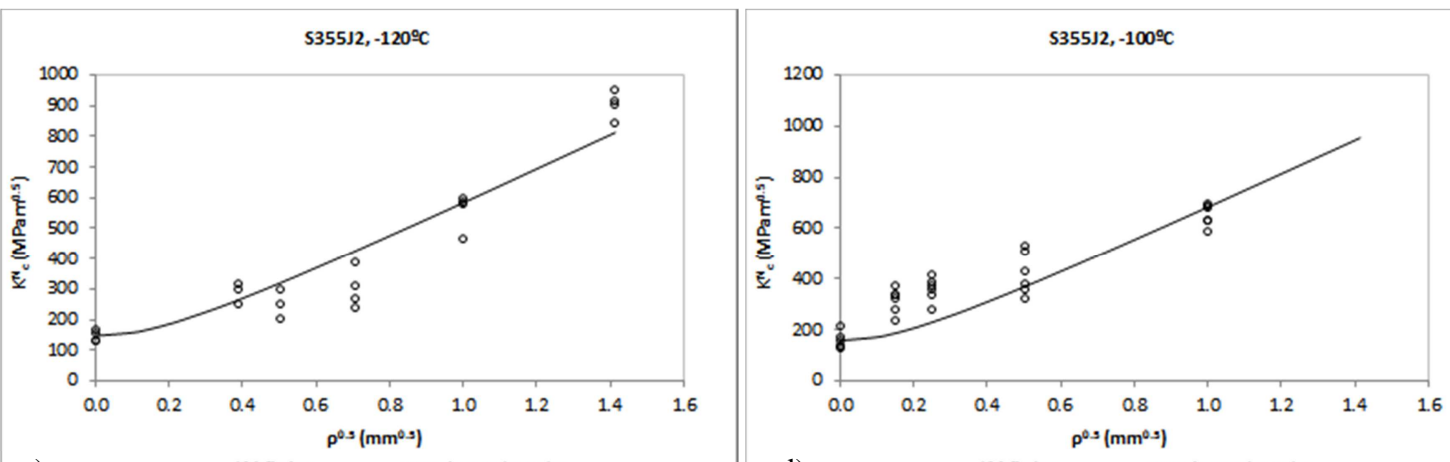

c)

—UM fitting $\quad \circ$ experimental results

d) $\quad$ UM fitting experimental results

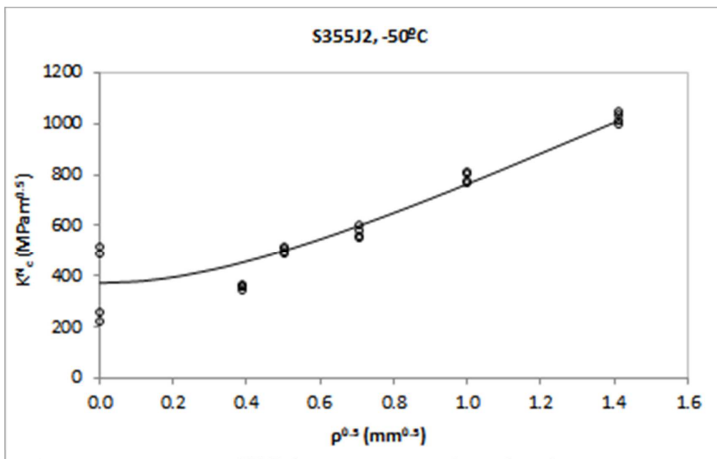

e)

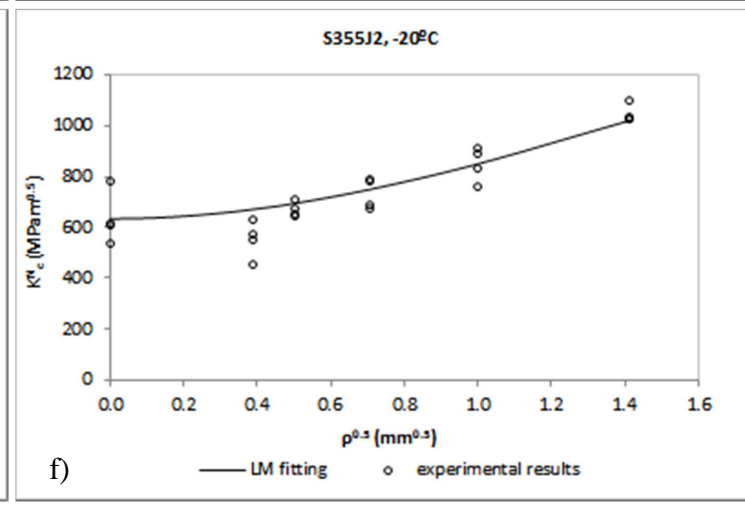

Figure 4. Experimental notch fracture toughness results, Line Method (LM) fitting and derivation of the corresponding critical distance. Steel S355J2. a) $-196^{\circ} \mathrm{C}$; b) $-150^{\circ} \mathrm{C}$; c) $-120^{\circ} \mathrm{C}$; d) $-100^{\circ} \mathrm{C}$; e) $-50^{\circ} \mathrm{C}$; f) $20^{\circ} \mathrm{C}$. 

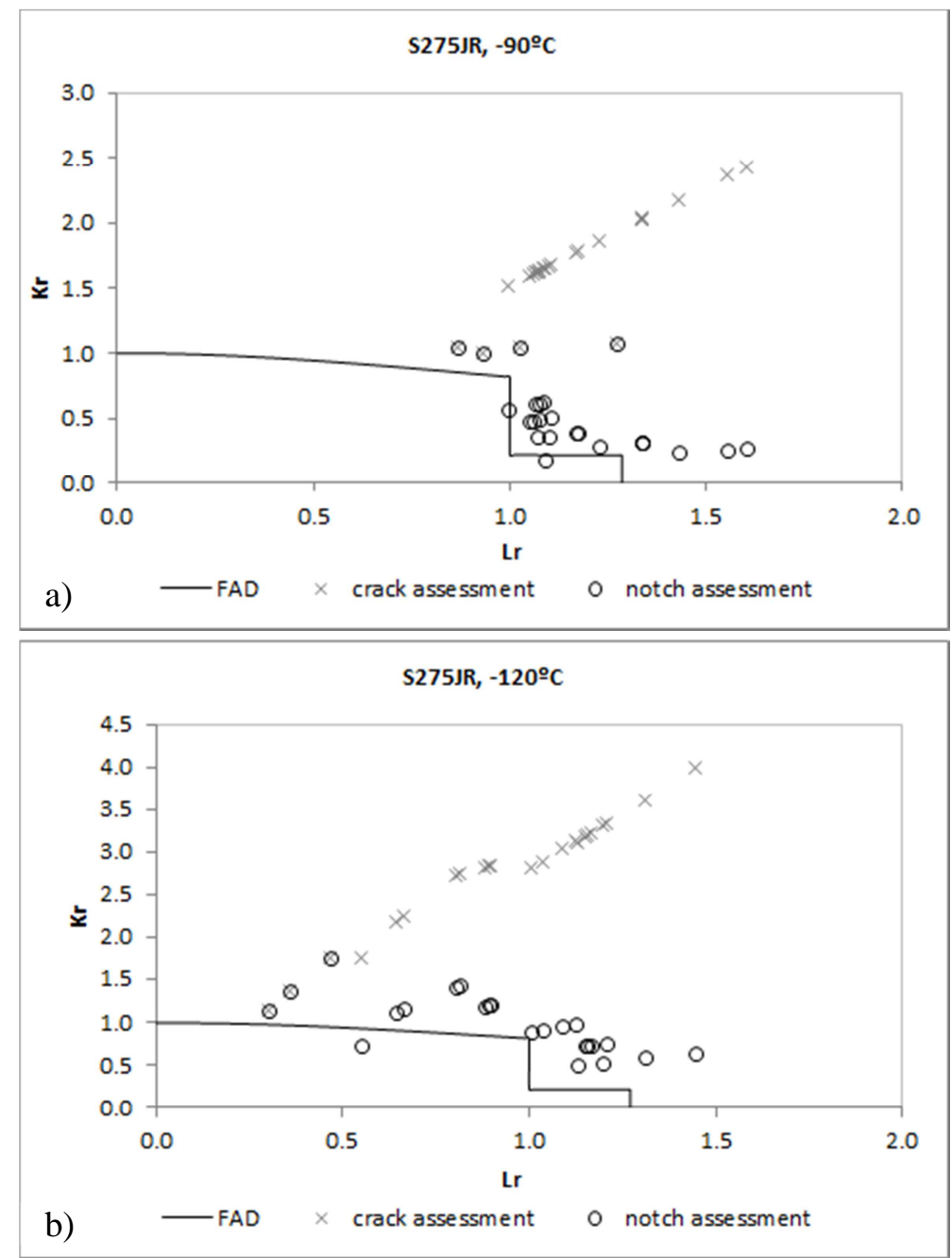

Figure 5. FAD assessment of S275JR specimens at the lower shelf, with (notch assessment) and without (crack assessment) the consideration of the notch effect. Fracture toughness of the material associated with a $95 \%$ confidence level. a) $-90^{\circ} \mathrm{C}$; b) $-120^{\circ} \mathrm{C}$. 


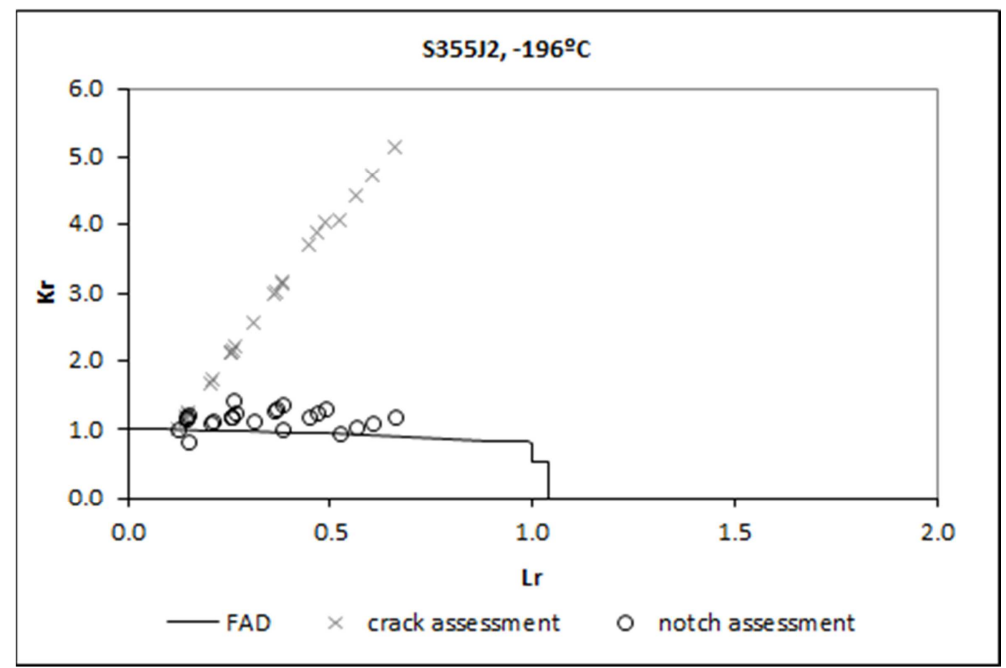

Figure 6. FAD assessment of S355J2 specimens at the lower shelf $\left(-196^{\circ} \mathrm{C}\right)$ with (notch assessment) and without (crack assessment) the consideration of the notch effect. Fracture toughness of the material associated with a 95\% confidence level. 


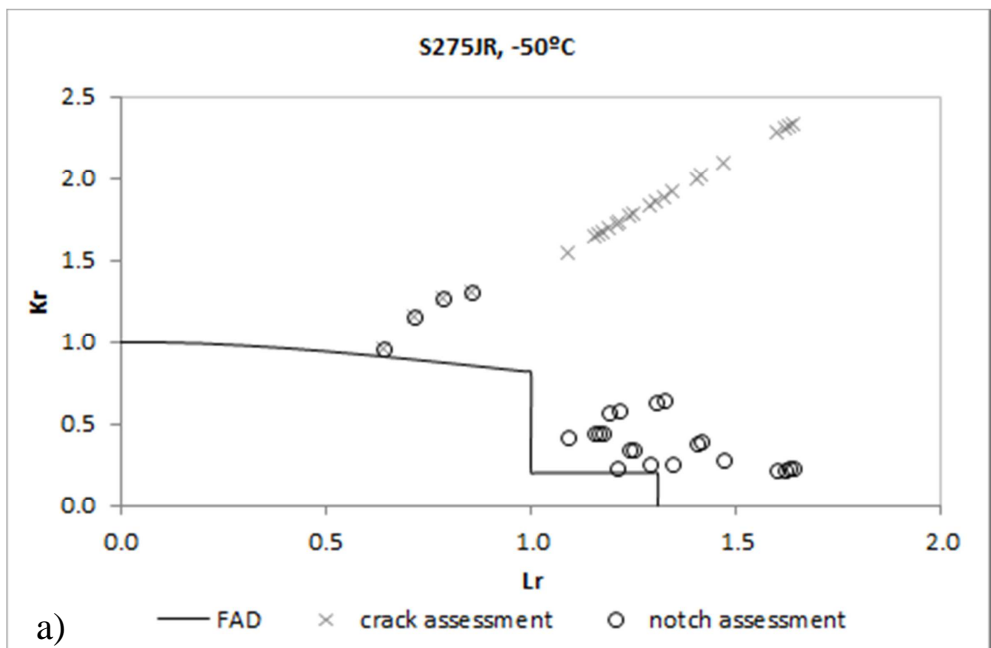

a)

S275JR, $-30 \% \mathrm{C}$

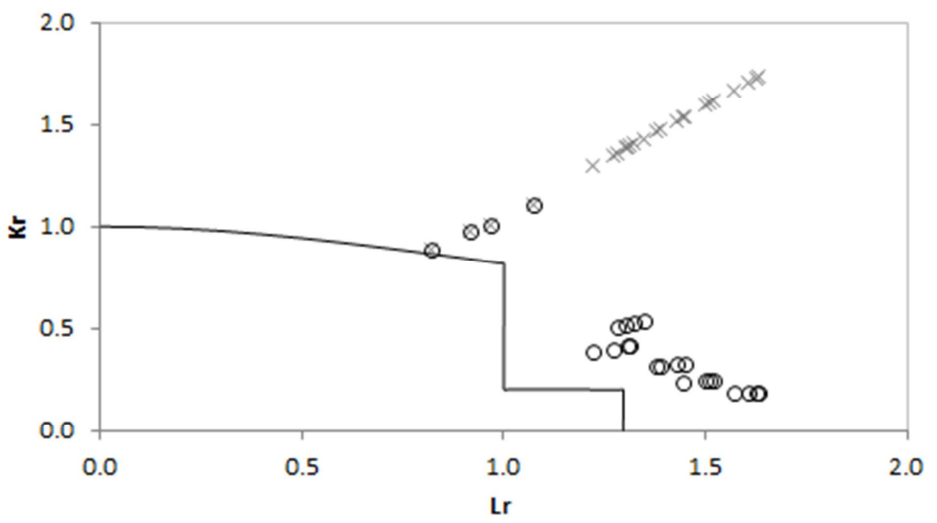

b) - FAD $\times$ crack assessment $\bigcirc$ notch assessment

S275JR, $-10 \div \mathrm{C}$

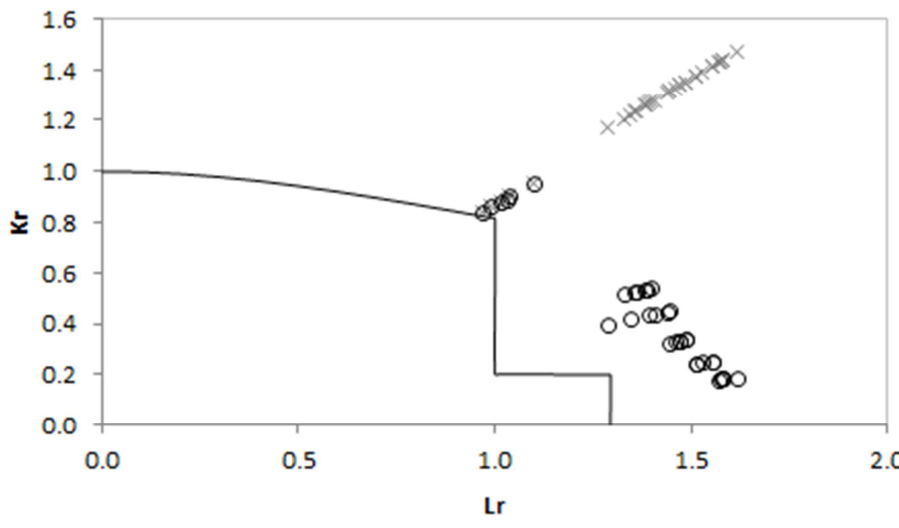

c) - FAD $\times$ crack assessment $\bigcirc$ notch assessment

Figure 7. FAD assessment of S275JR specimens at the DBTZ with (notch assessment) and without (crack assessment) the consideration of the notch effect. Fracture toughness of the material associated with a $95 \%$ confidence level. a) $-50^{\circ} \mathrm{C}$; b) $-30^{\circ} \mathrm{C}$; c) $-10^{\circ} \mathrm{C}$. 

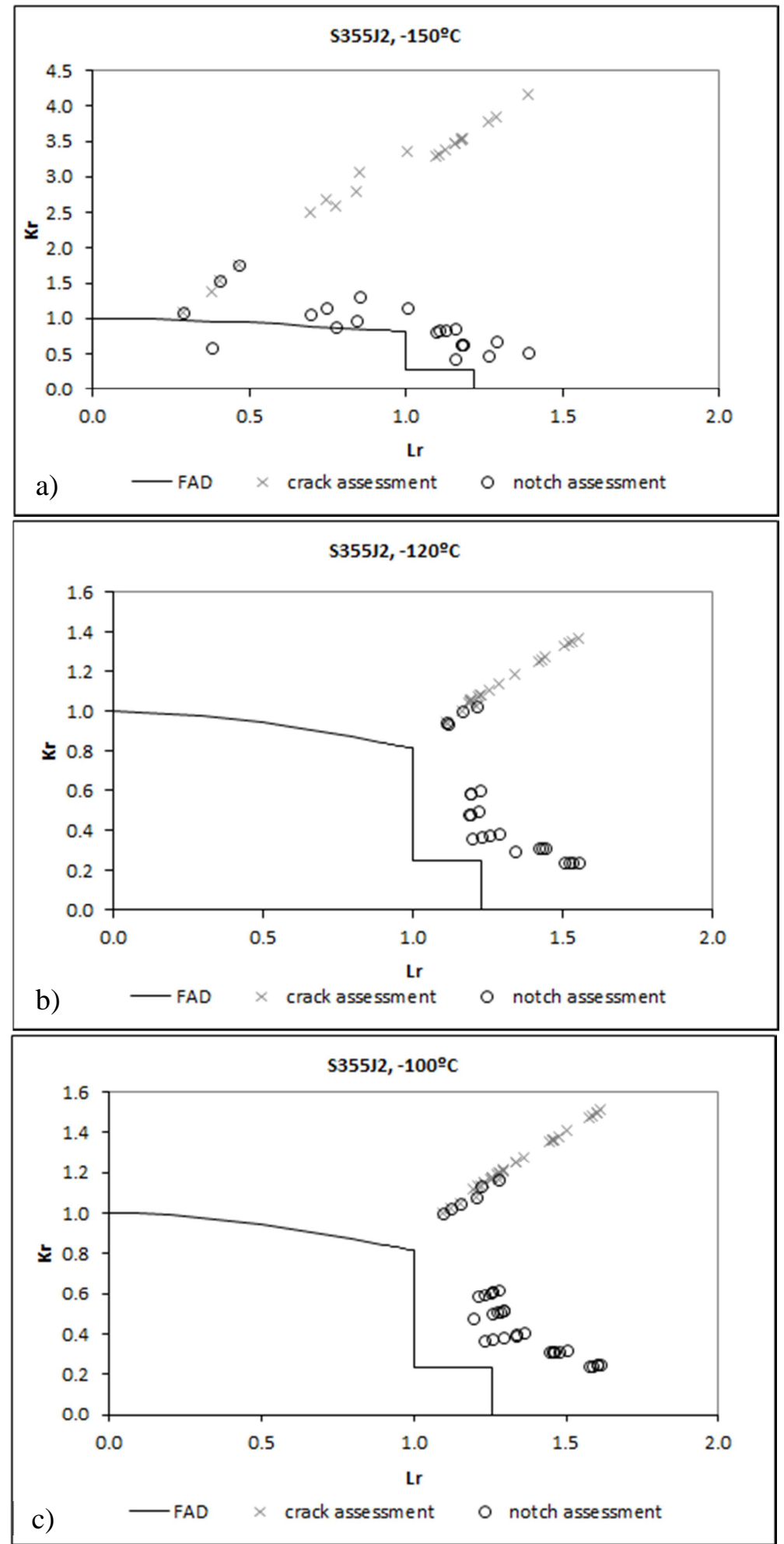

Figure 8. FAD assessment of S355J2 specimens at the DBTZ with (notch assessment) and without (crack assessment) the consideration of the notch effect. Fracture toughness of the material associated with a $95 \%$ confidence level. a) $-150^{\circ} \mathrm{C}$; b) $-120^{\circ} \mathrm{C}$; c) $-100^{\circ} \mathrm{C}$. 

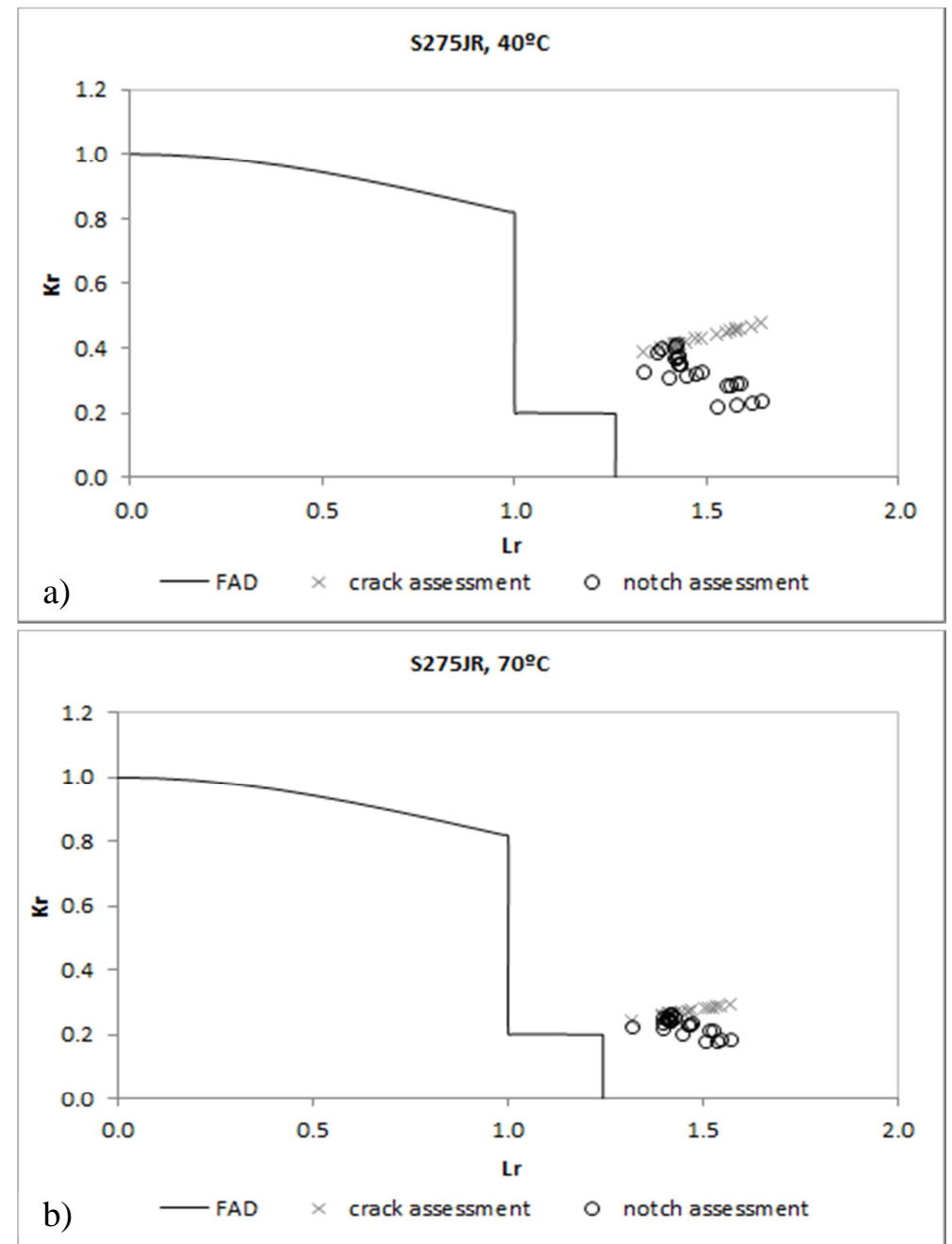

Figure 9. FAD assessment of S275JR specimens at the upper shelf with (notch assessment) and without (crack assessment) the consideration of the notch effect. Fracture toughness of the material associated with a $95 \%$ confidence level. a) $40{ }^{\circ} \mathrm{C}$; b) $70^{\circ} \mathrm{C}$. 

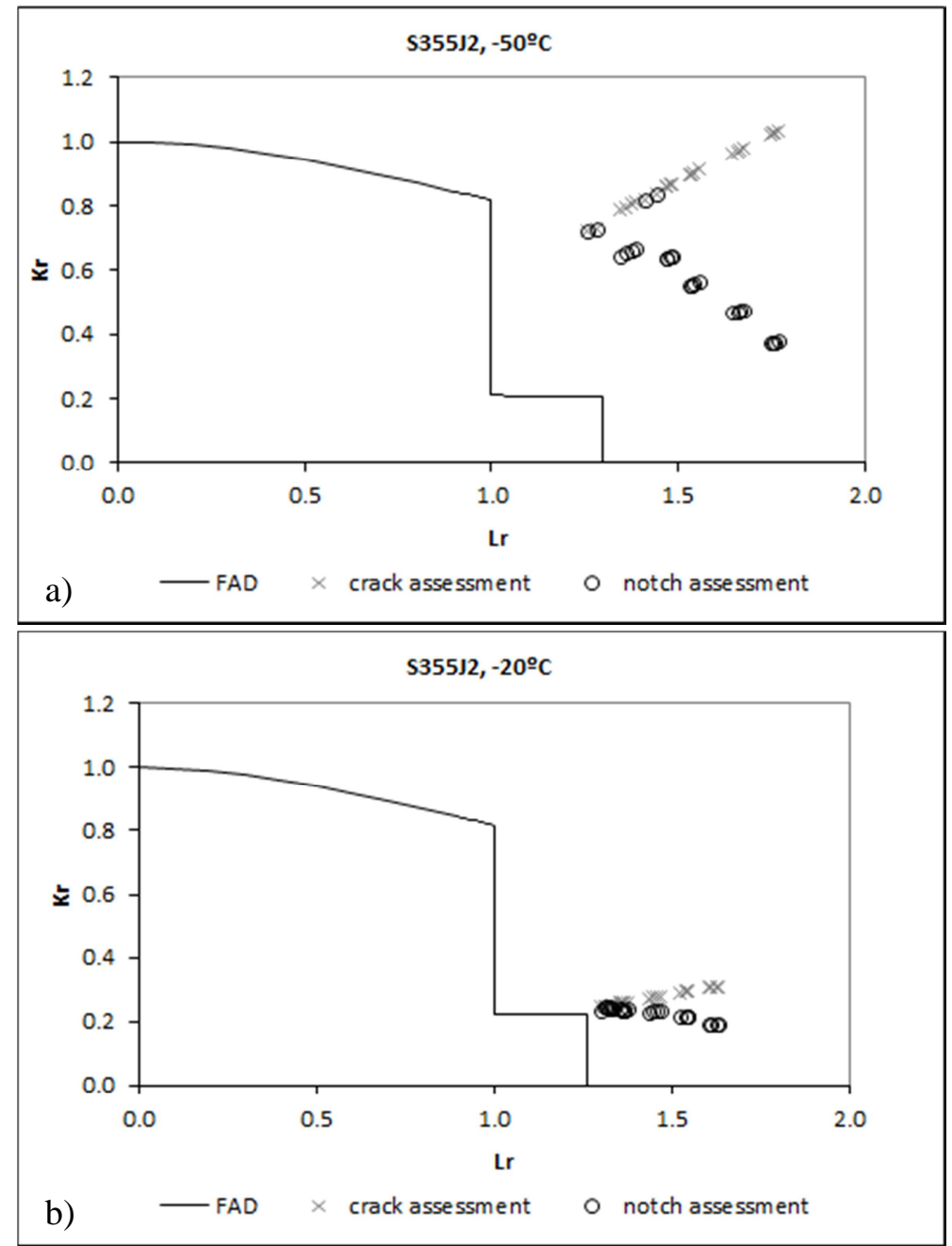

Figure 10. FAD assessment of S355J2 specimens at the upper shelf with (notch assessment) and without (crack assessment) the consideration of the notch effect. Fracture toughness of the material associated with a $95 \%$ confidence level. a) $-50{ }^{\circ} \mathrm{C}$; b) $-20^{\circ} \mathrm{C}$. 


\section{Tables}

Table 1. Testing temperatures for structural steels S275JR and S355J2.

\begin{tabular}{|l|l|l|}
\hline & S275JR & S355J2 \\
\hline Lower shelf & $-120^{\circ} \mathrm{C},-90^{\circ} \mathrm{C}$ & $-196^{\circ} \mathrm{C}$ \\
\hline DTBTZ & $-50^{\circ} \mathrm{C},-30^{\circ} \mathrm{C},-10^{\circ} \mathrm{C}$ & $-150^{\circ} \mathrm{C},-120^{\circ} \mathrm{C},-100^{\circ} \mathrm{C}$ \\
\hline Upper shelf & $40^{\circ} \mathrm{C}, 70^{\circ} \mathrm{C}$ & $-50^{\circ} \mathrm{C},-20^{\circ} \mathrm{C}$ \\
\hline
\end{tabular}


Table 2. Description of specimens and experimental results. Steel S275JR.

\begin{tabular}{|c|c|c|c|c|c|c|c|}
\hline Specimen & $\begin{array}{c}\text { Temperature } \\
\left({ }^{\circ} \mathrm{C}\right)\end{array}$ & $\begin{array}{c}\boldsymbol{\rho} \\
(\mathbf{m m})\end{array}$ & $\begin{array}{l}\mathbf{L B C} \\
(\mathbf{k N})\end{array}$ & Specimen & $\begin{array}{c}\text { Temperature } \\
\left({ }^{\circ} \mathrm{C}\right) \\
\end{array}$ & $\begin{array}{c}\rho \\
(\mathbf{m m})\end{array}$ & $\begin{array}{r}\mathbf{L B C} \\
(\mathrm{kN})\end{array}$ \\
\hline $2-1$ & \multirow{24}{*}{$\begin{array}{l}-120 \\
(\mathrm{LS})\end{array}$} & \multirow{4}{*}{0} & 23.3 & $2-49$ & \multirow{24}{*}{$\begin{array}{c}-50 \\
(\mathrm{DBTZ})\end{array}$} & \multirow{4}{*}{0} & 24.0 \\
\hline $2-2$ & & & 35.2 & $2-50$ & & & 38.2 \\
\hline $2-3$ & & & 28.0 & $2-51$ & & & 34.6 \\
\hline $2-4$ & & & - & $2-52$ & & & 34.9 \\
\hline $2-5$ & & \multirow{4}{*}{0.15} & 43.4 & $2-53$ & & \multirow{4}{*}{0.15} & 59.9 \\
\hline $2-6$ & & & 44.6 & $2-54$ & & & 58.5 \\
\hline $2-7$ & & & 54.9 & $2-55$ & & & 65.2 \\
\hline $2-8$ & & & 54.1 & $2-56$ & & & 64.2 \\
\hline $2-9$ & & \multirow{4}{*}{0.25} & 56.3 & $2-57$ & & \multirow{4}{*}{0.25} & 57.0 \\
\hline $2-10$ & & & 34.9 & $2-58$ & & & 58.0 \\
\hline $2-11$ & & & 55.8 & $2-59$ & & & 57.4 \\
\hline $2-12$ & & & 56.6 & $2-60$ & & & 53.6 \\
\hline $2-13$ & & \multirow{4}{*}{0.50} & 60.6 & $2-61$ & & \multirow{4}{*}{0.50} & 61.5 \\
\hline $2-14$ & & & 57.5 & $2-62$ & & & 61.1 \\
\hline $2-15$ & & & 55.9 & $2-63$ & & & 69.8 \\
\hline $2-16$ & & & 62.5 & $2-64$ & & & 69.2 \\
\hline $2-17$ & & \multirow{4}{*}{1.0} & 66.5 & $2-65$ & & \multirow{4}{*}{1.0} & 59.5 \\
\hline $2-18$ & & & 63.2 & $2-66$ & & & 66.3 \\
\hline $2-19$ & & & 64.0 & $2-67$ & & & 63.5 \\
\hline $2-20$ & & & 63.6 & $2-68$ & & & 72.5 \\
\hline $2-21$ & & \multirow{4}{*}{2.0} & 62.1 & $2-69$ & & \multirow{4}{*}{2.0} & 80.8 \\
\hline $2-22$ & & & 79.5 & $2-70$ & & & 80.3 \\
\hline $2-23$ & & & 71.9 & $2-71$ & & & 79.8 \\
\hline $2-24$ & & & 65.8 & $2-72$ & & & 78.9 \\
\hline $2-25$ & \multirow{24}{*}{$\begin{array}{l}-90 \\
(\mathrm{LS})\end{array}$} & \multirow{4}{*}{0} & 29.8 & $2-73$ & & \multirow{4}{*}{0} & 37.1 \\
\hline $2-26$ & & & 34.6 & $2-74$ & & & 33.6 \\
\hline $2-27$ & & & 33.8 & $2-75$ & & & 38.5 \\
\hline $2-28$ & & & 37.6 & $2-76$ & & & 36.0 \\
\hline $2-29$ & & \multirow{4}{*}{0.15} & 57.0 & $2-77$ & & \multirow{4}{*}{0.15} & 63.1 \\
\hline $2-30$ & & & 52.9 & $2-78$ & & & 65.4 \\
\hline $2-31$ & & & 57.7 & $2-79$ & & & 64.1 \\
\hline $2-32$ & & & 56.5 & $2-80$ & & & 62.1 \\
\hline $2-33$ & & \multirow{4}{*}{0.25} & 57.0 & $2-81$ & & \multirow{4}{*}{0.25} & 63.6 \\
\hline $2-34$ & & & 55.6 & $2-82$ & & & 63.4 \\
\hline $2-35$ & & & 58.7 & $2-83$ & & & 61.6 \\
\hline $2-36$ & & & 56.4 & $2-84$ & -30 & & 59.2 \\
\hline $2-37$ & & & 56.8 & $2-85$ & (DBTZ) & & 66.9 \\
\hline $2-38$ & & & 62.4 & $2-86$ & & & 69.3 \\
\hline $2-39$ & & 0.50 & 58.4 & $2-87$ & & 0.50 & 70.3 \\
\hline $2-40$ & & & 62.0 & $2-88$ & & & 67.3 \\
\hline $2-41$ & & & 71.1 & $2-89$ & & & 73.2 \\
\hline $2-42$ & & & 65.2 & $2-90$ & & & 72.9 \\
\hline $2-43$ & & 1.0 & 71.0 & $2-91$ & & 1.0 & 70.0 \\
\hline $2-44$ & & & 71.0 & $2-92$ & & & 73.7 \\
\hline $2-45$ & & & 57.9 & $2-93$ & & & 79.1 \\
\hline $2-46$ & & 20 & 76.0 & $2-94$ & & 20 & 76.3 \\
\hline $2-47$ & & 2.0 & 82.5 & $2-95$ & & 2.0 & 77.9 \\
\hline $2-48$ & & & 85.1 & $2-96$ & & & 78.9 \\
\hline
\end{tabular}


Table 2. Description of specimens and experimental results. Steel S275JR (cont.).

\begin{tabular}{|c|c|c|c|c|c|c|c|}
\hline Specimen & $\begin{array}{c}\text { Temperature } \\
\left({ }^{\circ} \mathrm{C}\right)\end{array}$ & $\begin{array}{c}\rho \\
(\mathbf{m m})\end{array}$ & $\begin{array}{r}\mathbf{L B C} \\
(\mathbf{k N}) \\
\end{array}$ & Specimen & $\begin{array}{c}\text { Temperature } \\
\left({ }^{\circ} \mathrm{C}\right)\end{array}$ & $\begin{array}{c}\rho \\
(\mathbf{m m})\end{array}$ & $\begin{array}{r}\mathbf{L B C} \\
(\mathrm{kN})\end{array}$ \\
\hline $2-97$ & \multirow{36}{*}{$\begin{array}{c}-10 \\
(\mathrm{DBTZ})\end{array}$} & \multirow{6}{*}{0} & 43.0 & $2-139$ & \multirow{18}{*}{$\begin{array}{l}+40 \\
(\mathrm{US})\end{array}$} & \multirow{2}{*}{0.15} & 64.7 \\
\hline $2-98$ & & & 39.3 & $2-140$ & & & 64.5 \\
\hline $2-99$ & & & 39.3 & $2-141$ & & \multirow{4}{*}{0.25} & 64.9 \\
\hline $2-100$ & & & 40.4 & $2-142$ & & & 64.8 \\
\hline $2-101$ & & & 37.1 & $2-143$ & & & 60.6 \\
\hline $2-102$ & & & 39.2 & $2-144$ & & & 64.8 \\
\hline $2-103$ & & \multirow{6}{*}{0.15} & 63.0 & $2-145$ & & \multirow{4}{*}{0.50} & 65.6 \\
\hline $2-104$ & & & 65.8 & $2-146$ & & & 66.9 \\
\hline $2-105$ & & & 66.4 & $2-147$ & & & 67.3 \\
\hline $2-106$ & & & 65.6 & $2-148$ & & & 63.6 \\
\hline $2-107$ & & & 64.4 & $2-149$ & & \multirow{4}{*}{1.0} & 71.9 \\
\hline $2-108$ & & & 64.6 & $2-150$ & & & 71.5 \\
\hline $2-109$ & & \multirow{6}{*}{0.25} & 66.1 & $2-151$ & & & 70.3 \\
\hline $2-110$ & & & 63.8 & $2-152$ & & & 70.9 \\
\hline $2-111$ & & & 66.7 & $2-153$ & & \multirow{4}{*}{2.0} & 74.6 \\
\hline $2-112$ & & & 68.3 & $2-154$ & & & 73.3 \\
\hline $2-113$ & & & 68.6 & $2-155$ & & & 71.5 \\
\hline $2-114$ & & & 61.0 & $2-156$ & & & 69.4 \\
\hline $2-115$ & & \multirow{6}{*}{0.50} & 69.4 & $2-157$ & \multirow{24}{*}{$\begin{array}{l}+70 \\
(\mathrm{US})\end{array}$} & \multirow{4}{*}{0} & 62.4 \\
\hline $2-116$ & & & 69.9 & $2-158$ & & & 62.8 \\
\hline $2-117$ & & & 69.8 & $2-159$ & & & 57.3 \\
\hline $2-118$ & & & 68.6 & $2-160$ & & & 59.0 \\
\hline $2-119$ & & & 70.5 & $2-161$ & & \multirow{4}{*}{0.15} & 63.8 \\
\hline $2-120$ & & & 70.6 & $2-162$ & & & 62.9 \\
\hline $2-121$ & & \multirow{6}{*}{1.0} & - & $2-163$ & & & 63.8 \\
\hline 2-122 & & & 71.8 & $2-164$ & & & 63.2 \\
\hline $2-123$ & & & 71.8 & $2-165$ & & \multirow{4}{*}{0.25} & 58.8 \\
\hline $2-124$ & & & 73.9 & $2-166$ & & & 63.5 \\
\hline $2-125$ & & & 73.8 & $2-167$ & & & 63.1 \\
\hline $2-126$ & & & 71.7 & $2-168$ & & & 62.5 \\
\hline $2-127$ & & \multirow{6}{*}{2.0} & 74.8 & $2-169$ & & \multirow{4}{*}{0.50} & 62.5 \\
\hline $2-128$ & & & - & $2-170$ & & & 65.5 \\
\hline $2-129$ & & & 75.0 & $2-171$ & & & 65.9 \\
\hline $2-130$ & & & 76.8 & $2-172$ & & & 65.6 \\
\hline 2-131 & & & 75.1 & $2-173$ & & \multirow{4}{*}{1.0} & 67.8 \\
\hline $2-132$ & & & 74.6 & $2-174$ & & & 64.8 \\
\hline $2-133$ & \multirow{6}{*}{$\begin{array}{l}+40 \\
\text { (US) }\end{array}$} & \multirow{4}{*}{0} & 59.0 & $2-175$ & & & - \\
\hline 2-134 & & & 62.1 & $2-176$ & & & 68.3 \\
\hline $2-135$ & & & 65.2 & 2-177 & & \multirow{4}{*}{2.0} & 70.1 \\
\hline $2-136$ & & & 62.9 & $2-178$ & & & 68.7 \\
\hline 2-137 & & \multirow{2}{*}{0.15} & 64.6 & $2-179$ & & & 67.4 \\
\hline $2-138$ & & & 64.3 & $2-180$ & & & 69.2 \\
\hline
\end{tabular}


Table 3. Description of specimens and experimental results. Steel S355J2.

\begin{tabular}{|c|c|c|c|c|c|c|c|}
\hline Specimen & $\begin{array}{c}\text { Temperature } \\
\left({ }^{\circ} \mathrm{C}\right)\end{array}$ & $\begin{array}{c}\boldsymbol{\rho} \\
(\mathbf{m m})\end{array}$ & $\begin{array}{r}\mathbf{L B C} \\
(\mathbf{k N}) \\
\end{array}$ & Specimen & $\begin{array}{c}\text { Temperature } \\
\left({ }^{\circ} \mathrm{C}\right)\end{array}$ & $\begin{array}{c}\rho \\
(\mathbf{m m})\end{array}$ & $\begin{array}{r}\mathbf{L B C} \\
(\mathrm{kN})\end{array}$ \\
\hline $3-1$ & \multirow{24}{*}{$\begin{array}{l}-196 \\
(\mathrm{LS})\end{array}$} & \multirow{4}{*}{0} & 18.5 & $3-49$ & & \multirow{4}{*}{0} & 60.5 \\
\hline 3-2 & & & 15.0 & $3-50$ & & & 60.5 \\
\hline 3-3 & & & 18.6 & $3-51$ & & & 56.2 \\
\hline $3-4$ & & & 17.9 & 3-52 & & & 54.1 \\
\hline $3-5$ & & \multirow{4}{*}{0.15} & 26.7 & 3-53 & & \multirow{4}{*}{0.15} & 73.3 \\
\hline $3-6$ & & & 19.7 & 3-54 & & & - \\
\hline $3-7$ & & & 27.3 & $3-55$ & & & 73.2 \\
\hline 3-8 & & & 34.3 & $3-56$ & & & 75.3 \\
\hline 3-9 & & \multirow{4}{*}{0.25} & 33.8 & $3-57$ & & \multirow{4}{*}{0.25} & - \\
\hline 3-10 & & & 33.5 & 3-58 & & & 75.1 \\
\hline 3-11 & & & 35.0 & 3-59 & & & 73.4 \\
\hline 3-12 & & & 33.6 & $3-60$ & -120 & & 72.9 \\
\hline $3-13$ & & \multirow{4}{*}{0.50} & 47.9 & 3-61 & (DBTZ) & \multirow{4}{*}{0.50} & 77.1 \\
\hline 3-14 & & & 49.9 & 3-62 & & & 79.1 \\
\hline $3-15$ & & & 47.2 & 3-63 & & & 75.4 \\
\hline $3-16$ & & & 40.9 & 3-64 & & & 73.7 \\
\hline $3-17$ & & \multirow{4}{*}{1.0} & 58.7 & 3-65 & & \multirow{4}{*}{1.0} & 87.3 \\
\hline 3-18 & & & 61.5 & $3-66$ & & & 87.8 \\
\hline 3-19 & & & 50.1 & 3-67 & & & 88.5 \\
\hline $3-20$ & & & 63.9 & 3-68 & & & 82.5 \\
\hline $3-21$ & & \multirow{4}{*}{2.0} & 74.8 & 3-69 & & \multirow{4}{*}{2.0} & 95.4 \\
\hline $3-22$ & & & 81.6 & 3-70 & & & 92.6 \\
\hline 3-23 & & & 70.1 & 3-71 & & & 94.3 \\
\hline $3-24$ & & & 64.6 & 3-72 & & & 93.7 \\
\hline $3-25$ & \multirow{24}{*}{$\begin{array}{c}-150 \\
(\mathrm{DBTZ})\end{array}$} & \multirow{4}{*}{0} & - & 3-73 & & \multirow{6}{*}{0} & 54.6 \\
\hline $3-26$ & & & 21.0 & 3-74 & & & 54.6 \\
\hline 3-27 & & & 30.4 & 3-75 & & & 53.1 \\
\hline 3-28 & & & 34.4 & 3-76 & & & 61.5 \\
\hline 3-29 & & \multirow{4}{*}{0.15} & 71.7 & 3-77 & & & 61.2 \\
\hline $3-30$ & & & 31.9 & 3-78 & & & 55.0 \\
\hline 3-31 & & & 62.5 & 3-79 & & \multirow{6}{*}{0.15} & 70.6 \\
\hline 3-32 & & & 58.5 & 3-80 & & & 74.5 \\
\hline 3-33 & & \multirow{4}{*}{0.25} & 65.4 & 3-81 & & & 72.8 \\
\hline 3-34 & & & 78.3 & 3-82 & & & 73.2 \\
\hline 3-35 & & & 60.2 & 3-83 & & & 73.3 \\
\hline $3-36$ & & & - & 3-84 & -100 & & 71.8 \\
\hline 3-37 & & \multirow{4}{*}{0.50} & 81.0 & 3-85 & (DBTZ) & \multirow{6}{*}{0.25} & 75.2 \\
\hline 3-38 & & & 77.4 & 3-86 & & & 75.3 \\
\hline 3-39 & & & 78.7 & 3-87 & & & 74.1 \\
\hline $3-40$ & & & 76.7 & $3-88$ & & & 74.6 \\
\hline $3-41$ & & & 82.4 & 3-89 & & & 73.2 \\
\hline $3-42$ & & 10 & 82.1 & 3-90 & & & 69.7 \\
\hline $3-43$ & & 1.0 & 89.8 & 3-91 & & & 71.7 \\
\hline $3-44$ & & & 82.4 & 3-92 & & & 77.8 \\
\hline $3-45$ & & & 97.0 & 3-93 & & & 79.5 \\
\hline $3-46$ & & 20 & - & 3-94 & & 0.50 & 73.3 \\
\hline $3-47$ & & 2.0 & 88.1 & 3-95 & & & 75.4 \\
\hline $3-48$ & & & 80.8 & $3-96$ & & & 77.9 \\
\hline
\end{tabular}


Table 3. Description of specimens and experimental results. Steel S355J2 (cont.).

\begin{tabular}{|c|c|c|c|c|c|c|c|}
\hline Specimen & $\begin{array}{c}\text { Temperature } \\
\left({ }^{\circ} \mathrm{C}\right)\end{array}$ & $\begin{array}{c}\mathbf{\rho} \\
(\mathbf{m m})\end{array}$ & $\begin{array}{l}\mathbf{L B C} \\
(\mathbf{k N})\end{array}$ & Specimen & $\begin{array}{c}\text { Temperature } \\
\left({ }^{\circ} \mathrm{C}\right)\end{array}$ & $\begin{array}{c}\rho \\
(\mathbf{m m})\end{array}$ & $\begin{array}{l}\text { LBC } \\
(\mathbf{k N})\end{array}$ \\
\hline 3-97 & \multirow{12}{*}{$\begin{array}{c}-100 \\
(\mathrm{DBTZ})\end{array}$} & \multirow{6}{*}{1.0} & 87.7 & 3-127 & \multirow{6}{*}{$\begin{array}{l}-50 \\
\text { (US) }\end{array}$} & \multirow{2}{*}{1.0} & 84.0 \\
\hline 3-98 & & & 84.9 & 3-128 & & & 83.7 \\
\hline 3-99 & & & 85.0 & 3-129 & & \multirow{4}{*}{2.0} & 87.6 \\
\hline 3-100 & & & 84.3 & 3-130 & & & 87.9 \\
\hline 3-101 & & & 85.9 & 3-131 & & & 88.1 \\
\hline 3-102 & & & 85.0 & 3-132 & & & 88.7 \\
\hline 3-103 & & \multirow{6}{*}{2.0} & 93.3 & 3-133 & \multirow{24}{*}{$\begin{array}{l}-20 \\
\text { (US) }\end{array}$} & \multirow{4}{*}{0} & 65.2 \\
\hline 3-104 & & & 93.4 & 3-134 & & & 61.3 \\
\hline 3-105 & & & 94.1 & 3-135 & & & 67.7 \\
\hline 3-106 & & & 92.4 & 3-136 & & & 67.4 \\
\hline 3-107 & & & 91.8 & 3-137 & & \multirow{4}{*}{0.15} & 68.8 \\
\hline 3-108 & & & - & 3-138 & & & 70.5 \\
\hline 3-109 & \multirow{18}{*}{$\begin{array}{l}-50 \\
\text { (US) }\end{array}$} & \multirow{4}{*}{0} & 69.1 & 3-139 & & & 71.6 \\
\hline 3-110 & & & 69.9 & 3-140 & & & 71.4 \\
\hline 3-111 & & & 58.9 & 3-141 & & \multirow{4}{*}{0.25} & 72.8 \\
\hline 3-112 & & & 60.0 & 3-142 & & & 72.3 \\
\hline 3-113 & & \multirow{4}{*}{0.15} & 68.9 & 3-143 & & & 72.0 \\
\hline 3-114 & & & 68.3 & 3-144 & & & 71.8 \\
\hline 3-115 & & & 67.4 & $2-145$ & & \multirow{8}{*}{0.50} & 77.5 \\
\hline 3-116 & & & 69.5 & 3-146 & & & 76.6 \\
\hline 3-117 & & \multirow{4}{*}{0.25} & 74.5 & 3-147 & & & 75.9 \\
\hline 3-118 & & & 73.7 & 3-148 & & & 77.0 \\
\hline 3-119 & & & 74.2 & 3-149 & & & 81.5 \\
\hline 3-120 & & & 73.8 & 3-150 & & & 81.8 \\
\hline 3-121 & & \multirow{4}{*}{0.50} & 77.1 & 3-151 & & & 81.3 \\
\hline 3-122 & & & 76.7 & 3-152 & & & 80.5 \\
\hline 3-123 & & & 77.3 & 3-153 & & \multirow{4}{*}{2.0} & 84.9 \\
\hline 3-124 & & & 78.2 & 3-154 & & & 85.8 \\
\hline $3-125$ & & \multirow{2}{*}{1.0} & 82.6 & 3-155 & & & 86.1 \\
\hline 3-126 & & & 83.3 & $3-156$ & & & 84.9 \\
\hline
\end{tabular}


Table 4. Tensile properties of steel S275JR

\begin{tabular}{|c|c|c|c|c|}
\hline Material & Temperature $\left({ }^{\mathbf{0}} \mathbf{C}\right)$ & $\mathbf{E}(\mathbf{G P a})$ & $\boldsymbol{\sigma}_{\mathbf{v}}(\mathbf{M P a})$ & $\boldsymbol{\sigma}_{\mathbf{u}}(\mathbf{M P a})$ \\
\hline \multirow{4}{*}{ S275JR } & +70 & 203 & 331.7 & 492.7 \\
\cline { 2 - 5 } & +40 & 205 & 331.0 & 504.7 \\
\cline { 2 - 5 } & +20 & 207 & 328.4 & 518.5 \\
\cline { 2 - 5 } & -10 & 207 & 337.6 & 536.3 \\
\cline { 2 - 5 } & -30 & 208 & 344.5 & 548.6 \\
\cline { 2 - 5 } & -50 & 209 & 349.1 & 564.7 \\
\cline { 2 - 5 } & -90 & 211 & 380.2 & 597.3 \\
\hline
\end{tabular}


Table 5. Tensile properties of steel S355J2

\begin{tabular}{|c|c|c|c|c|}
\hline Material & Temperature $\left({ }^{\mathbf{C}} \mathbf{C}\right)$ & $\mathbf{E}(\mathbf{G P a})$ & $\boldsymbol{\sigma}_{\mathbf{v}}(\mathbf{M P a})$ & $\boldsymbol{\sigma}_{\mathbf{u}}(\mathbf{M P a})$ \\
\hline \multirow{4}{*}{ S355J2 } & +20 & 207 & 374.6 & 557.6 \\
\cline { 2 - 5 } & -20 & 208 & 385.3 & 587.7 \\
\cline { 2 - 5 } & -50 & 209 & 395.3 & 602.7 \\
\cline { 2 - 5 } & -100 & 212 & 426.2 & 646.5 \\
\cline { 2 - 5 } & -120 & 212 & 459.8 & 671.6 \\
\cline { 2 - 5 } & -150 & 215 & 527.5 & 757.9 \\
\cline { 2 - 5 } & -196 & 218 & 853.5 & 922.9 \\
\hline
\end{tabular}


Table 6. $\mathrm{K}_{\mathrm{c}}$ values for steel S275JR.

\begin{tabular}{|c|c|c|c|}
\hline $\begin{array}{c}\mathbf{T} \\
\left({ }^{\circ} \mathbf{C}\right)\end{array}$ & $\begin{array}{c}\mathbf{K}_{\mathrm{c}} \\
\left(\mathrm{MPam}^{1 / 2}\right)\end{array}$ & $\begin{array}{l}\mathbf{K}_{\mathrm{c}}(50 \%) \\
\left(\mathrm{MPam}^{1 / 2}\right)\end{array}$ & $\begin{array}{l}\mathbf{K}_{\mathrm{c}}(95 \%) \\
\left(\mathrm{MPam}^{1 / 2}\right)\end{array}$ \\
\hline \multirow{4}{*}{$\begin{array}{l}-120 \\
(\mathrm{LS})\end{array}$} & 39.2 & \multirow{4}{*}{48.8} & \multirow{4}{*}{34.4} \\
\hline & 60.4 & & \\
\hline & 46.8 & & \\
\hline & - & & \\
\hline \multirow{4}{*}{$\begin{array}{c}-90 \\
(\text { LS })\end{array}$} & 64.6 & \multirow{4}{*}{62.7} & \multirow{4}{*}{60.3} \\
\hline & 60.5 & & \\
\hline & 63.1 & & \\
\hline & 62.7 & & \\
\hline \multirow{4}{*}{$\begin{array}{c}-50 \\
\text { (DBTZ) }\end{array}$} & 61.3 & \multirow{4}{*}{80.6} & \multirow{4}{*}{59.8} \\
\hline & 88.0 & & \\
\hline & 78.1 & & \\
\hline & 95.0 & & \\
\hline \multirow{4}{*}{$\begin{array}{c}-30 \\
(\text { DBTZ) }\end{array}$} & 104.2 & \multirow{4}{*}{100.7} & \multirow{4}{*}{79.0} \\
\hline & 80.8 & & \\
\hline & 100.1 & & \\
\hline & 117.7 & & \\
\hline \multirow{6}{*}{$\begin{array}{c}-10 \\
\text { (DBTZ) }\end{array}$} & 148.5 & \multirow{6}{*}{122.8} & \multirow{6}{*}{90.2} \\
\hline & 97.0 & & \\
\hline & 105.8 & & \\
\hline & 124.2 & & \\
\hline & 148.1 & & \\
\hline & 113.2 & & \\
\hline \multirow{4}{*}{$\begin{array}{c}+40 \\
(\mathrm{US})\end{array}$} & 354.1 & \multirow{4}{*}{504.8} & \multirow{4}{*}{271.0} \\
\hline & 484.9 & & \\
\hline & 736.9 & & \\
\hline & 443.2 & & \\
\hline \multirow{4}{*}{$\begin{array}{c}+70 \\
(\mathbf{U S})\end{array}$} & 1040.0 & \multirow{4}{*}{771.1} & \multirow{4}{*}{415.3} \\
\hline & 650.4 & & \\
\hline & 494.6 & & \\
\hline & 924.3 & & \\
\hline
\end{tabular}


Table 7. $\mathrm{K}_{\mathrm{c}}$ values for steel S355J2.

\begin{tabular}{|c|c|c|c|}
\hline $\begin{array}{c}\mathbf{T} \\
\left({ }^{\mathbf{o}} \mathbf{C}\right) \\
\end{array}$ & $\begin{array}{c}\mathbf{K}_{\mathrm{c}} \\
\left(\mathrm{MPam}^{1 / 2}\right)\end{array}$ & $\begin{array}{c}\mathbf{K}_{\mathrm{c}}(50 \%) \\
\left(\mathrm{MPam}^{1 / 2}\right) \\
\end{array}$ & $\begin{array}{c}\mathrm{K}_{\mathrm{c}}(95 \%) \\
\left(\mathrm{MPam}^{1 / 2}\right) \\
\end{array}$ \\
\hline \multirow{4}{*}{$\begin{array}{l}-196 \\
(L S)\end{array}$} & 32.2 & \multirow{4}{*}{31.3} & \multirow{4}{*}{27.4} \\
\hline & 27.3 & & \\
\hline & 33.5 & & \\
\hline & 32.1 & & \\
\hline \multirow{4}{*}{$\begin{array}{c}-150 \\
\text { (DBTZ) }\end{array}$} & - & \multirow{4}{*}{60.6} & \multirow{4}{*}{40.3} \\
\hline & 44.3 & & \\
\hline & 63.3 & & \\
\hline & 74.1 & & \\
\hline \multirow{4}{*}{$\begin{array}{c}-120 \\
\text { (DBTZ) }\end{array}$} & 169.5 & \multirow{4}{*}{146.6} & \multirow{4}{*}{120.4} \\
\hline & 153.4 & & \\
\hline & 132.6 & & \\
\hline & 130.9 & & \\
\hline \multirow{6}{*}{$\begin{array}{c}-100 \\
\text { (DBTZ) }\end{array}$} & 136.9 & \multirow{6}{*}{157.5} & \multirow{6}{*}{107.7} \\
\hline & 136.1 & & \\
\hline & 126.8 & & \\
\hline & 216.6 & & \\
\hline & 170.5 & & \\
\hline & 158.0 & & \\
\hline \multirow{4}{*}{$\begin{array}{c}\mathbf{- 5 0} \\
(\mathbf{U S})\end{array}$} & 491.1 & \multirow{4}{*}{372.1} & \multirow{4}{*}{148.3} \\
\hline & 516.9 & & \\
\hline & 259.1 & & \\
\hline & 221.4 & & \\
\hline \multirow{4}{*}{$\begin{array}{c}-\mathbf{2 0} \\
(\mathrm{US})\end{array}$} & 782.1 & \multirow{4}{*}{635.6} & \multirow{4}{*}{481.1} \\
\hline & 609.1 & & \\
\hline & 537.0 & & \\
\hline & 614.3 & & \\
\hline
\end{tabular}


Table 8. L values for each material and temperature.

\begin{tabular}{|c|c|c|}
\hline Steel & $\begin{array}{c}\text { Temperature } \\
\left({ }^{\mathbf{}} \mathbf{C}\right)\end{array}$ & $\begin{array}{c}\mathbf{L} \\
(\mathbf{m m})\end{array}$ \\
\hline \multirow{4}{*}{ S275JR } & -120 & 0.0137 \\
\cline { 2 - 3 } & -90 & 0.0062 \\
\cline { 2 - 3 } & -50 & 0.0049 \\
\cline { 2 - 3 } & -30 & 0.0061 \\
\cline { 2 - 3 } & -10 & 0.0083 \\
\cline { 2 - 3 } & 40 & 0.1697 \\
\hline \multirow{4}{*}{ S355J2 } & 70 & 0.3421 \\
\cline { 2 - 3 } & -196 & 0.0291 \\
\cline { 2 - 3 } & -150 & 0.0084 \\
\cline { 2 - 3 } & -120 & 0.0168 \\
\cline { 2 - 3 } & -100 & 0.0140 \\
\cline { 2 - 3 } & -50 & 0.0778 \\
\hline
\end{tabular}

